\title{
A RADIOMETRIC INVESTIGATION OF THE GERMI- CIDAL ACTION OF ULTRA-VIOLET RADIATION
}

\author{
By W. W. Coblentz and H. R. Fulton
}

ABSTRACT

In the present investigation an attempt is made to determine the energy relations involved in abiotic action, thus placing the results upon a radiometric basis. By means of screens of mica, and of glass, successive portions of the ultra-violet spectrum are eliminated and the effects upon the resulting germicidal action established. The novelty in the present investigation consisted in making an application of the discovery that mica has a well-defined absorption band at about $260 \mathrm{~m} \mu$. A small variation in thickness of the mica screen produces a large variation in transmission in this spectral region relative to the rest of the spectrum, thereby permitting an increase in the intensity of the radiation stimulus of these wave lengths, while other conditions remained practically constant.

The effects of preexposure of the culture medium upon subsequent inoculation were investigated, and found negligible for the intensities and the time of exposure used in this investigation.

The paper gives data on ( $I$ ) the effect of continuous and of intermittent exposure; (2) the spectral range of, as well as the effect of the intensity of the radiation stimulus upon abiotic action; and (3) the energy required to kill a bacterium.

For low intensities a stimulation of bacterial growth may possibly occur, which is a question requiring further investigation.

\section{CONTENTS}

I. Introduction $\ldots \ldots \ldots \ldots \ldots$

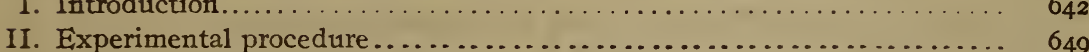

I. General arrangement of the ultra-violet radiator............. 649

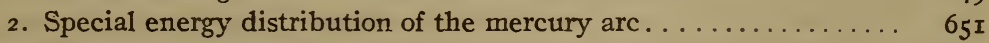

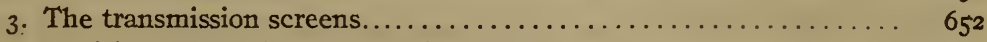

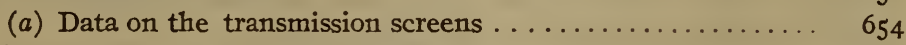

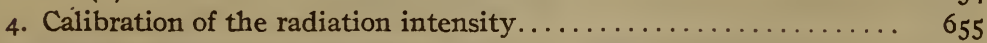

5. Spectral transmission of some culture media and amino acids.... 658

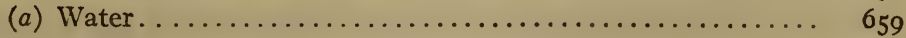

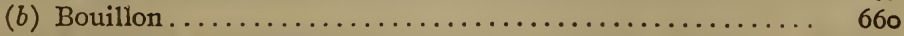

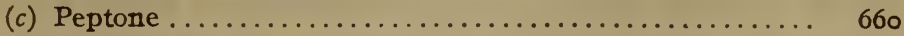

(d) Tyrosin and phenylalanin....................... $66 \mathrm{r}$

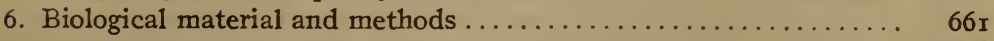

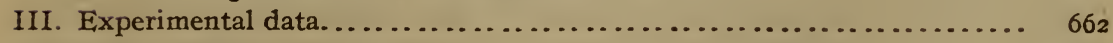

I. Effect of ultra-violet light upon the culture medium......... $66_{2}$

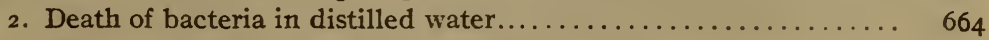

3. Effect of continuous and intermittent exposure............ 665 
III. Experimental data-Continued.

4. Spectral range of abiotic action $\ldots \ldots \ldots \ldots \ldots \ldots \ldots \ldots \ldots \ldots, 666$

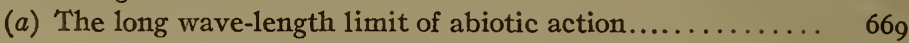

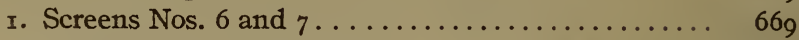

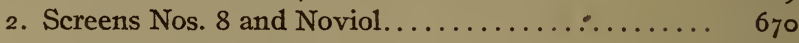

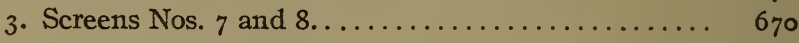

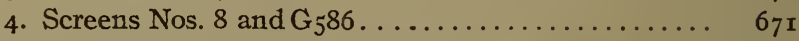

(b) Shielding action of the culture medium............. $6_{72}$

(c) Abiotic action through screens of solutions of amino acids. . 673

5. Effect of intensity upon abiotic action . . . . . . . . . . . . . $6_{74}$

6 . The energy required to kill a bacterium................. 676

(a) Abiotic action. No screen .................... 677

(b) Abiotic action. Mica screen No. $2 \ldots \ldots \ldots \ldots \ldots \ldots \ldots \ldots, 6 \ldots \ldots$

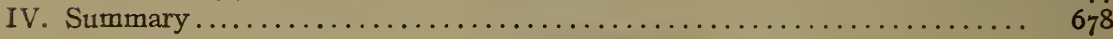

\section{INTRODUCTION}

Frequent requests are received for information on the photochemical and abiotic action of ultra-violet rays in dye fading, water sterilization, injurious effects upon the eyes, etc.

These questions have been the subject of numerous investigations from the standpoint of biologists, chemists, and physicists. A perusal of the literature on the subject shows, in many cases, incompleteness of experimental procedure, and sometimes flagrant inconsistencies in the conclusions.

The present investigation had its beginning in the strictly utilitarian question of the practicability of exposing fruit (for example, oranges) to ultra-violet light in order to destroy the mold spores thereon, before wrapping and packing, thus reducing the loss caused by decay, which is of great importance to the producer, vender, and consumer. The investigation was extended to the general subject of germicidal action as affected by the wave length and the intensity of, as well as the method of exposure (whether continuous or intermittent) to, the exciting light.

While no claim can be made for completeness, the results thus far obtained serve to clear up several mooted questions, as well as to show some interesting relations between chemical and physical agencies which produce germicidal effects.

Since, as already stated, the literature is replete with investigations on the germicidal action of ultra-violet light, ${ }^{1}$ it seems sufficient to refer only to some of the papers which are pertinent to

\footnotetext{
${ }^{1}$ See a bibliography of 32 references on water sterilization in a paper by Houghton and Davis, Amer. Jour: of Public Health, 4, p. 224; 19r4; also a book just issued by M. Iuckiesh on ultra-violet radiation, its properties, production, measurement, and applications. A paper on the uses and possibilities of ultraviolet light, by Krueger, Gen. Elect. Rev., 25, p. 316 , 1922; gives a discussion and an extensive bibliography of various recent researches involving the application of ultra-violet radiation. A very complete bibliography of the physiological and biological effects of ultra-violet radiation is given in a paper by E. Mayer, Amer. Rev. of Tuberculosis, 5, p. 75 ; $192 \mathrm{x}$.
} 
the questions discussed in the present communication. From the experimental data at hand it appears that the wave-length limit of germicidal action, as well as the abiotic action upon living tissue in general, is rather indefinite.

Two methods, in general, have been used in attacking this problem: (I) By exposure of the material covered with screens which absorb certain wave lengths of the ultra-violet and (2) by exposure of the material to the ultra-violet spectrum produced by a quartz spectrograph.

In the experiments of Henri ${ }^{2}$ and his collaborators using the mercury-vapor arc in quartz, also the spark between electrodes of cadmium and of magnesium as sources of radiation, filtered through transmission screens of glass, and of celluloid, which were placed over the material investigated, it was found that the destructive action of the light increased as the wave length decreased. The bactericidal action of rays longer than $305 \mathrm{~m} \mu$ was extremely slow, requiring three to five hours to sterilize an emulsion of Bacillus coli instead of only I $_{5}$ to 20 seconds when using wave lengths shorter than $305 \mathrm{~m} \mu$. They found that the rate of killing is different for different kinds of bacteria; also that the germicidal action decreases more rapidly than the inverse square of the distance from the source. In other words, as will be shown in the present paper, the killing action is proportionately much slower for low than for high intensities.

Similar investigations by Verhoeff and $\mathrm{Bell}^{3}$ on eye media, show that the abiotic action on living tissue is confined practically to wave lengths shorter than $305 \mathrm{~m} \mu$. Moreover, within wide limits, discontinuous exposures to abiotic rays had the same total effect as a continuous exposure of the same total length of time. In other words, using intensities above a certain energy level, the effect of the abiotic action was found to be cumulative in its injurious effect upon the eye.

The action of the ultra-violet rays of very short wave lengths, known as the Schumann rays $(\lambda \lambda \mathrm{I} 25$ to $\mathrm{I} 70 \mathrm{~m} \mu)$ upon living organisms has been studied by Bovie. ${ }^{4}$ He made no radiometric measurements. However, it is fairly well established that the Schumann ${ }^{5}$ radiation of the hydrogen discharge tube is of low intensity. Nevertheless, he found the Schumann rays very

\footnotetext{
${ }^{2}$ Cernovodenau and Henri, Compt. Rend., 135, p. $315 ;$ 1902; 150, pp. 52 and 549; rgro; Henri, Compt. Rend., 155, p. 315; 1912.

${ }^{3}$ Verhoeff and Bell, Proc. Amer. Acad. Arts and Sci., 51, p. 640; 19r6. (See extensive bibliography.

4 Bovie, Botanical Gazette, 61, p. г; 19г6. (Good bibliography.)

Pflüger, Ann. der Phys. (4), 13, p. 909; r904.
} 
destructive to protoplasm. The action of the light is shown to be exerted directly upon the organism and not indirectly through the formation of some toxic substance in the medium. But it is necessary for the rays to penetrate the cell wall of the organism. For this reason he selected organisms having thin, transparent cell walls. Fungus spores, with brown or tan coloring matter in their cell walls, even though the walls were thin, were not killed by a prolonged exposure to the Schumann rays.

The window of the vacuum discharge tube containing hydrogen, was of fluorite, which is transparent to wave lengths longer than I25 $\mathrm{m} \mu .^{6}$ Interposing a rock-salt screen which is opaque to radiation of wave lengths less than $\mathrm{I} 7 \mathrm{O} \mathrm{m} \mu$, Bovie found that, in the Schumann region of the spectrum as in the region of longer wave length (200 to $300 \mathrm{~m} \mu$ ) the destructive action of the light increases as the wave length decreases. The action of the light was 15 to 20 times more destructive when it contained the short waves than when these short rays were filtered out. He concluded that the radiation in the Schumann region is much more destructive than the rays of longer wave length; and that the destructive action of the ultra-violet rays is continued into the Schumann region of the spectrum without changing its character. It is of interest to add that he found that, if the decomposition of the protein molecule is not carried too far, there is a stimulation of the cell. This stimulation phenomenon has been observed by a number of investigators, but apparently has not been given a thorough study. It is, therefore, proposed to include this question in a continuation of the present investigation.

Turning now to some of the experiments with spectrally isolated radiation stimuli we find more discordant and sometimes inconsistent results. Frequently no radiometric measurements were made of the spectral intensities; and in some cases where reference is made to the use of spectral lines having the same intensity no information is given as to the manner in which this was established.

Among the early investigations of the physiological action of spectral radiation upon living tissues is that of Hertel, 7 wo used lenses and a prism of quartz to form the spectrum of the light from spark gaps of various metals. The spectral intensities were measured by means of a thermopile. He found that the abiotic action of the light varies directly as the energy and inversely as the wave length.

${ }^{8}$ Lyman, Astrophys. Jour., 25, p. 45; 1907.

${ }^{7}$ Hertel, Zeitschr. f. Allgem. Physiol., 5, pp. 95 and 534; 1905. 
Bazzoni ${ }^{8}$ has published some experiments on the destruction of bacteria through the action of ultra-violet light. Using isolated emission lines from the mercury arc he found that, after a threehour exposure, the number of living bacteria (B.typhosus) was as follows: Wave length of exciting radiation, 220, 236, and $253 \mathrm{~m} \mu$, respectively; number of bacteria remaining $\mathrm{I} / 80, \mathrm{I} / 50$, and $\mathrm{I} / \mathrm{I} 2$, respectively. This shows the very rapid increase in bactericidal action with decrease in wave length. For, as will be shown presently, if it were a question only of the intensity of the exciting radiation (see fig. 2), then the $253 \mathrm{~m} \mu$ line should have killed the greatest number of bacteria.

Bazzoni observed that the killing effect of the total radiation from the mercury arc is much more rapid than that of the isolated wave lengths. But he seems to have overlooked the fact that some of the wave lengths selected for his experiments are weak radiometrically; also that there is considerable continuous spectrum, so that the effect of a single wave length is insignificant as compared with the combined action of all the rays having germicidal properties. He concluded that the destructive effect of the ultra-violet radiation is in some way dependent on its association with radiation of greater wave length and greater penetrating power.

Instead of taking the view of Bazzoni that the presence of the long wave-length radiation accelerates bactericidal action of the short wave lengths the reverse might be said, viz, a little ultraviolet radiation of short wave lengths mixed with the long wavelength radiation accelerates the bactericidal action of the long wave lengths.

But it is highly probable that this same amount of ultra-violet radiation, acting without the presence of the longer wave lengths, would produce the same bactericidal action as would be obtained with the presence of the longer wave lengths. It is not an easy matter to make the test in this manner. The present investigation, in which increasing amounts of short wave length ultra-violet radiation are added to the radiation stimulus of longer wave lengths, seems to indicate that the bactericidal action is not necessarily associative, but is a function of the wave length and the intensity of the particular lethal radiation used.

An interesting investigation of the germicidal action of ultraviolet radiation and its correlation with selective absorption has

${ }^{8}$ Bazzoni, Amer. Jour. Publ. Health, 4, p. 975 ; 19r4. 
been published recently by Browning and Russ. ${ }^{9}$ The method employed consisted in coating a glass plate with a thin layer of nutrient agar, painting it with microorganisms, and exposing it in the spectrum of a quartz spectrograph. The source of radiation was an arc of pure tungsten. After exposure and incubation, that part of the plate extending from wave lengths 294 to $238 \mathrm{~m} \mu$ was found covered with clear lines coinciding with the emission lines which had produced a bactericidal effect.

No data are at hand concerning the spectral energy distribution in the tungsten arc. Hence, nothing can be said regarding the sharp termination of the germicidal action in the short wavelengths, which result seems contrary to general experience, and is probably owing to absorption in the instrument.

Their published photograph of the arc spectrum of tungsten appears weak for wave lengths less than $230 \mathrm{~m} \mu$. This is owing, in part, to lack of sensitivity of the photographic plate in this spectral region, and especially to the high absorption in the quartz spectrograph for wave lengths less than $220 \mathrm{~m} \mu$. As already stated, no radiometric measurements of the ultra-violet spectral energy distribution of the tungsten arc have been published. Hence, part of the weak germicidal action in the short (less than 2 Io $\mathrm{m} \mu$ ) wave lengths may be owing to a weak spectral intensity of the arc. For, as mentioned in the above-cited investigation by Bovie, the germicidal action is very marked in the extremely short wave lengths.

Control experiments were made to determine whether the radiation had any effect upon the (uninoculated) agar. No difference was detected in the density of growth of the organisnas over the portions of the agar which were irradiated and nonirradiated before inoculation. This is in agreement with the results of the present investigation for the intensities actually used in our work.

The absorption spectrum of the bacterial emulsion was found to extend from 296 to 2 I $\mathrm{m} \mu$, which is the spectral range of germicidal action. In the present investigation, as will be shown presently, the high absorption of some nutrient media in the ultra-violet prevents bactericidal action in the very short wave lengths.

The spectral range of germicidal action was thought to be different for different organisms, exposed simultaneously. For

- Browning and Russ, Archives Radiology and Electrotherapy, 18, p. 85; 1918. 
$B$. coli the range of lethal effect extended from 296 to $220 \mathrm{~m} \mu$ and for B. typhosus it extended from 300 to 2 ro $\mathrm{m} \mu$. For Staphylocoscus pyogenes aureus the spectral range of greatest germicidal action extended from 296 to $238 \mathrm{~m} \mu$.

It was noted by Browning and Russ that the organisms appeared to be stimulated in their growth, in the region of the plate lying between two portions which had been exposed to the ultra-violet spectrum, though they do not attribute it necessarily to scattered radiation. As will be shown presently, such an increase is always observable in the shadowed portion of the Petri dish adjacent to the region exposed to the ultra-violet rays. A possible explanation is that along this edge the unaffected bacteria have a better chance for obtaining nutriment, and hence for better development, than in the more crowded part of the plate. Furthermore, our tests with the water suspensions, for short exposures, show a similar increase in bacteria per cubic centimeter, which may be attributed to erroneous experimental procedure in handling control samples. However, when considered in connection with the above-cited experiments of Bovie, also of Browning and Russ, there is some evidence that organisms are stimulated in growth when exposed to low-intensity ultra-violet radiation. As already mentioned, this is a phenomenon that will be given further study.

Mashimo ${ }^{10}$ has published the results of an investigation similar to that of Browning and Russ, but independent of it. As a source of radiation he used the condensed spark spectrum of iron. $\mathrm{He}$ exposed the bacteria in the spectrum for various intervals of time up to 40 minutes. He gives an excellent photograph of the incubated plate, upon which the ultra-violet spectrum has left an impression similar to that of a sensitized photographic plate.

The results obtained show that the bactericidal effect of the ultra-violet radiation begins at about $295 \mathrm{~m} \mu$, attains its maximum at $275 \mathrm{~m} \mu$, and then decreases slowly to $186 \mathrm{~m} \mu$, which, as noted elsewhere, is the beginning of atmospheric absorption. This effect seemed to be independent of the nature of the bacteria, and of the culture medium employed.

From tests made on bacteria exposed to the sun with and without glass screens of various thicknesses (I and ro $\mathrm{mm}$ ) intervening, he concluded that the most lethal part of the sunlight having a bactericidal action lies in the ultra-violet region of wave lengths less than $295 \mathrm{~m} \mu$.

${ }^{10}$ Mashimo, Mem. College of Sci., Kyoto Imperial Univ., 4, p. I; 1919. $832^{\circ}-24-2$ 
The slight discrepancy in the results of Browning and Russ and of Mashimo are attributable to experimental difficulties, such, for example, as the difficulty in controlling a metal arc. The results of Mashimo are particularly important in showing that there is no discontinuity in the germicidal action throughout the ultra-violet spectrum, extending into the Schumann region, investigated by Bovie (loc. cit.).

In most of the foregoing investigations the organism was in or upon a nutrient medium, which might have some protective effect from the abiotic rays. Newcomer ${ }^{11}$ tried to overcome this by using fresh-water suspensions of the organism (typhoid bacilli) in quartz capillary tubes, which were held in the spectrum produced by a quartz spectrograph. The source of ultra-violet radiation was a condensed iron spark; also sparks of copper and of zinc. The relative intensities in the spectrum were measured photographically, which, however, can not be considered a satisfactory means of estimation of energy distribution. After exposure (of 5 to Io minutes) the contents of the exposed quartz tubes were plated in melted agar, after which the plates were incubated and counts made. He obtained no killing action for wave lengths greater than about $300 \mathrm{~m} \mu$, which no doubt is owing in part to lack of intensity of the light. Exposure to sunlight for $20 \mathrm{~min}$ utes produced no effect.

To the foregoing somewhat inconsistent results may be added a very recent investigation of the bactericidal action of spectrally dispersed ultra-violet light, ${ }^{12}$ which included also a determination of the absorption spectrum of the bacteria, as well as the effects of temperature and of hydrogen-ion concentration of the culture medium. The culture of Staphylococcus aureus was spread upon a plate of nutrient agar and exposed to the spectrum of an iron spark. It was found that the lethal effect of the ultra-violet radiation upon bacteria is greatly accelerated in an acid medium; the velocity of the bactericidal action increased with increase in hydrogen-ion concentration.

It was established that the bactericidal action of the light begins at $350 \mathrm{~m} \mu$ and extends with increasing intensity to the shortest wave lengths at $185.6 \mathrm{~m} \mu$ transmitted by the quartz spectrograph. No energy measurements were made. The long wave-length limit of bactericidal action was established by exposing cultures of bacteria to the sun (for three hours) under screens

11 Newcomer, Jour. Exptal. Medicine, 26, p. 841; 1917.

12 Bayne-Jones and Van der Lingen, Johns Hopkins Hospital Bull., 34, p. I1; 1923. 
of quartz and of glass, including Crook's neutral tint glass, which is opaque to radiation of wave lengths less than about $350 \mathrm{~m} \mu$. Nevertheless, some bactericidal action was obtained through this glass.

This is in agreement with the results of the present investigation, in which, as will be shown presently, it was found that radiation of wave lengths 334 to $365 \mathrm{~m} \mu$ are bactericidal, disproving some of the inconsistent results cited in the foregoing pages.

In concluding this summary it is relevant to add that writers on this subject appropriately point out that the short wave-length limit of the solar spectrum is between 280 and $290 \mathrm{~m} \mu$, and hence living organisms are adapted to existence in sunlight. However, the time of exposure must also be considered, so that while the intensity of the solar rays lying between 290 and $305 \mathrm{~m} \mu$ is extremely small ${ }^{13}$ as compared with the mercury arc, it is nevertheless possible to produce germicidal action with sunlight, provided sufficient time is given in making the test.

\section{EXPERIMENTAL PROCEDURE}

The experimental procedure is not essentially different from that usually employed in investigations of this type. An attempt is made to present the results on a quantitative radiometric basis which seems to be the rational procedure in order to obtain some estimate of the germicidal action of different parts of the spectrum.

\section{GENERAL ARRANGEMENT OF THE ULTRA-VIOLET RADIATOR}

The mercury arc in an exhausted quartz vessel is a convenient and powerful source of ultra-violet radiation.

In the present investigation use was made of a I Io-volt quartz burner, having a mercury cathode and a tungsten anode. The current and voltage of this style of burner are subject to greater fluctuations than the all-mercury type of burner. While, for short exposures (say, one-tenth second) this fluctuation might introduce errors, in previous investigations of the emissive properties of these burners ${ }^{14}$ it was found that the average energy input and energy radiated is constant to within the limits of the experimental errors of other factors entering into the problems under investigation.

${ }_{13}$ Coblentz and Kahler, B. S. Sci. Papers, 16, p. 233 ; 1920 (No. 378).

14 B. S. Sci. Papers, 15, p. 1; 1918; 16, p. 233; 1920 (Nos. 330 and 378 ). 
The top, sides, and ends of this lamp were permanently inclosed in a metal box, as illustrated in Figure $\mathrm{I}$. The bottom of this box consisted of a shield (at a distance of about $6 \mathrm{~cm}$ from the burner) with a constant opening, $8 \mathrm{~cm}$ along the axis of the burner and ro $\mathrm{cm}$ in width, covered with an aluminum shutter, $A l$. This length of opening shielded the irradiated material from most of the radiation emanating from the incandescent tungsten anode. In order to vary the intensity (by $\mathrm{I} / \mathrm{IO}, \mathrm{I} / 2 \mathrm{O}, \mathrm{I} / 35$, and $\mathrm{r} / 5 \mathrm{O}$ ) of the total radiation, $I_{0}$, incident upon the material under investigation, this opening was covered lengthwise (that is, along the axis of the burner) with aluminum slits, $S l$, leaving openings 3 to $8 \mathrm{~mm}$ in
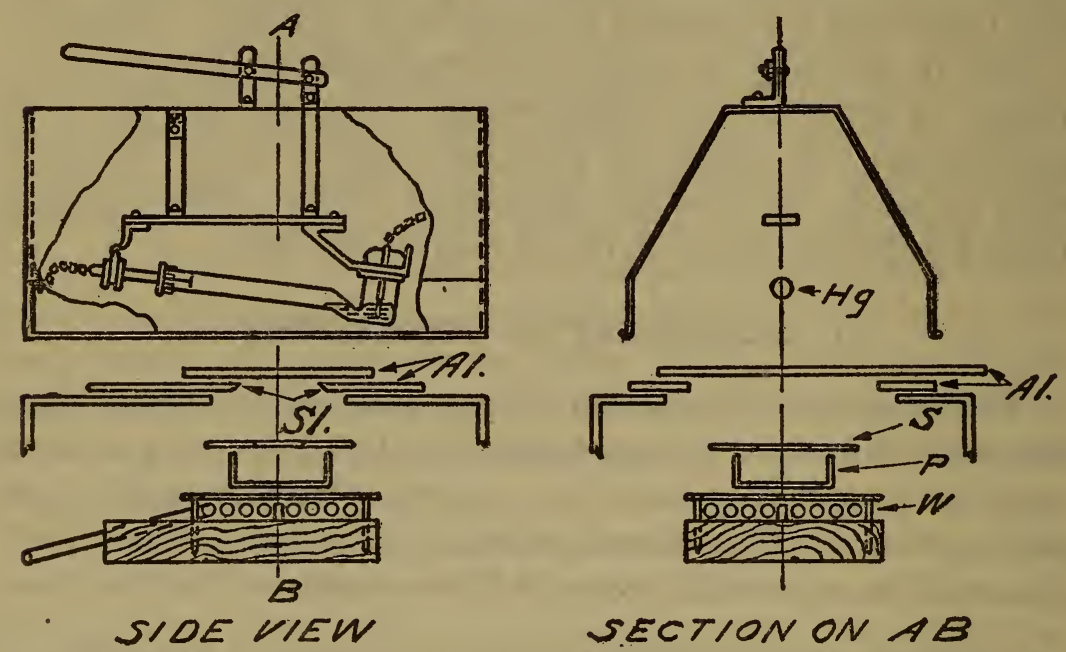

SECTION ON AB

FIG. I.-Arrangement of apparatus för studying bactericidal action of ultra-violet light

length. The width of the opening crosswise to the burner was kept large (ro $\mathrm{cm}$ ) to avoid errors that might arise from lateral displacement of the burner. A water-cooled stage, $W$, was used to maintain the irradiated material at a uniform temperature. This stage consisted of a copper plate ro by Io by $0.15 \mathrm{~cm}$ mounted in contact with a coil of thin-walled (O.I $\mathrm{mm}$ ) copper tubing through which water was circulated. The material under investigation (say, inoculated agar in a Petri dish, $P$ ) was placed upon this copper plate. As a further protection from the heat of the lamp an aluminum cover, $S$, with a suitable opening, was placed over the Petri dish.

For compactness and clearness, in this illustration (fig. $x$ ) the relative sizes and distances of the various parts of the apparatus are not drawn to scale. 


\section{SPECTRAL ENERGY DISTRIBUTION OF THE MERCURY ARC}

Data on the distribution of intensities in the spectral lines of the quartz mercury arc burner were published in previous papers. ${ }^{15}$ In a special investigation of the physical characteristics of the radiation from quartz mercury arc lamps it was shown ${ }^{16}$ that the type of contruction (whether only one or both electrodes are of mercury) has no appreciable effect upon the ultra-violet component radiation. It was found that the ultra-violet component decreases but slowly with usage. Furthermore, since the completion of those early investigations marked improvements have been

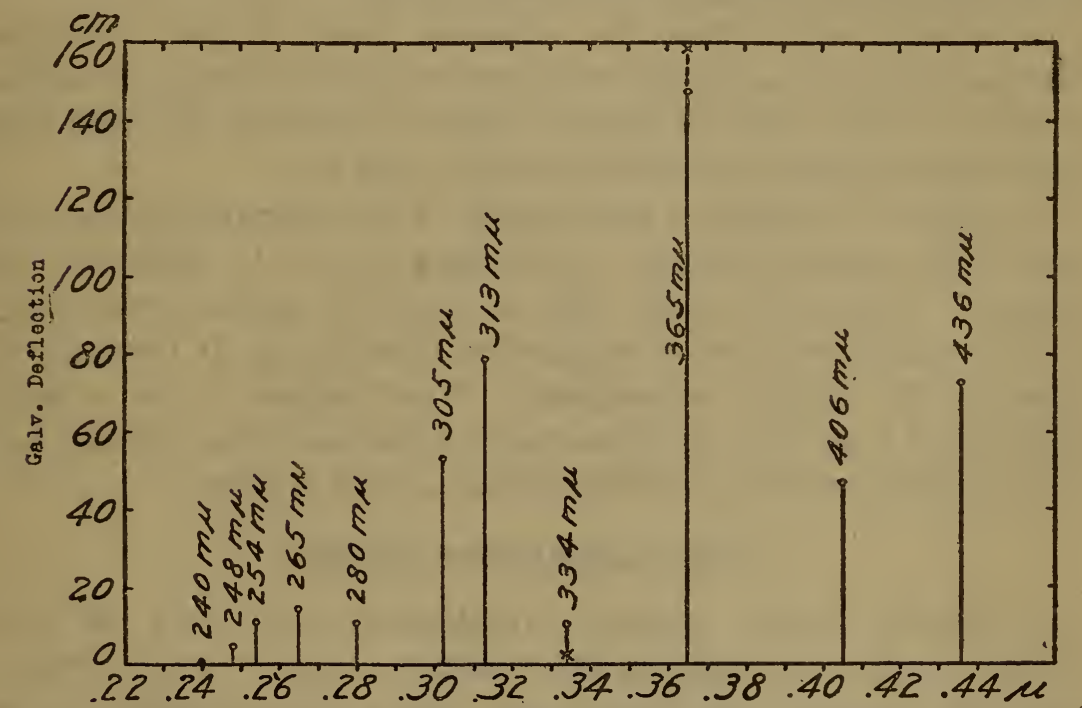

FIG. 2.-Radiometric intensities of the principal ultra-violet spectral lines in the quartz mercury arc

made in the construction of this type of burner, which blackens but little with usage.

The burner used in the present investigation was new and was maintained primarily for this work. Hence, the question of deterioration need not be considered.

During the course of this investigation a measurement was made of the ultra-violet component radiation of this burner, using the standard transmission screen of Corning Noviol glass, shade $B$, adopted in previous work. ${ }^{17}$ The ultra-violet component radiation of wave lengths less than $405 \mathrm{~m} \mu$ was 60 per cent of the total radiation of all wave lengths, less than $\mathrm{I}, 400 \mathrm{~m} \mu$, emanating

15 B. S. Sci. Papers, Nos. 330 and 378.

${ }^{16}$ Amer. Jour. Electrotherapeutics and Radiology, 39, p. 395; 1921.

${ }_{17}$ B. S. Sci. Papers, 15, p. $x$; 1918 (No. 330). 
from the burner, including the incandescent tungsten anode. This is in exact agreement with previous tests of new burners of this type.

The radiation intensities of the principal emission lines in the ultra-violet spectrum of this quartz mercury arc burner, on normal operation of 320 watts (80 volts, 4 amperes) are illustrated in Figure 2. The relative intensities seem to be somewhat different from that of a 220 -volt lamp described in a previous paper, ${ }^{18}$ which gives data also on the variation of intensity with power input, and a comparison of the ultra-violet emission spectrum of the sun and of the mercury arc.

It is to be noticed that the emission lines of wave lengths shorter than $305 \mathrm{~m} \mu$, which are known to produce strong germicidal action, are very weak in energy value as compared with the long wave-length limit of germicidal action- $365 \mathrm{~m} \mu$.

In Figure 3 is shown a photograph of the spectrum of the sun, and of the quartz mercury arc, prepared by C. C. Kiess, of this bureau. It may be noted that at sea-level stations practically no solar radiation of wave lengths less than $305 \mathrm{~m} \mu$ is transmitted through the earth's atmosphere. Nevertheless, it is a wellestablished fact that the ultra-violet radiation from the sun has a bactericidal action, provided sufficient time is given.

\section{THE TRANSMISSION SCREENS}

As already stated, previous investigators have used the subtractive method of applying the radiation stimulus by absorbing, first the shortest then longer and longer wave lengths of the lethal rays by means of screens. The present method may be called subtractive and additive. It is based upon the observation, which appears to be novel, that mica has an absorption band with a maximum in the region of $260 \mathrm{~m} \mu$. A small variation in thickness produces a relatively large variation in transmission in this spectral region as compared with the transmission at $365 \mathrm{~m} \mu$. This is illustrated in Figure 4, curves $3 a$ and $3 b$, which represent the spectral transmissions of a screen of mica, one part of which is thinner than the other. For the spectral region of 240 to $290 \mathrm{~m} \mu$ (having a high germicidal action, but low energy value for the quartz mercury arc) the thinner part of the screen transmits from 30 to 50 per cent more radiation than the thicker part of the screen, whereas for the spectral lines at 313,334 , and $365 \mathrm{~m} \mu$ the

${ }_{18}$ Coblentz, Amer. Jour. Electrotherapeutics and Radiology, 39, p. 395, r92r; also B. S. Sci. Papers, No. 330. 
Scientific Papers of the Bureau of Standards, Vol. 19

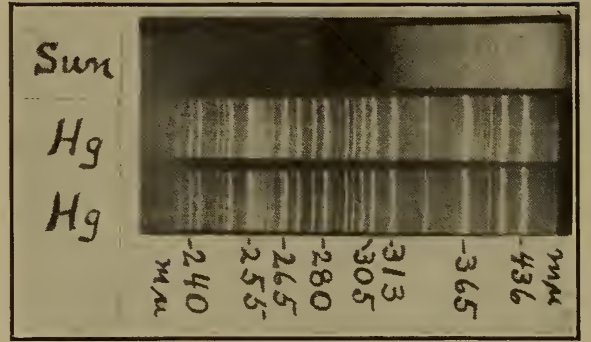

FIG. 3.-Spectrograms of the quartz mercury arc and of the sun

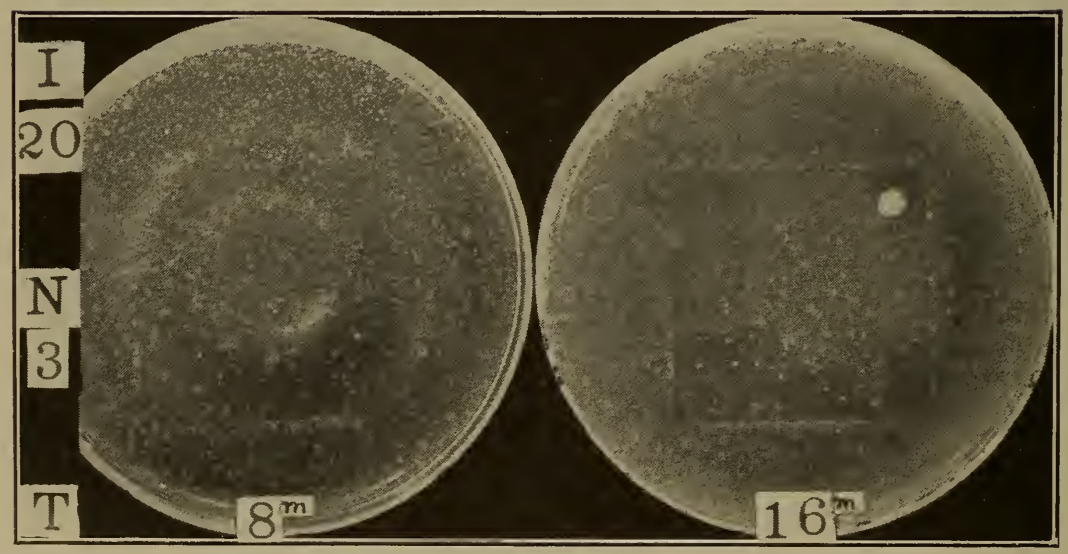

FIG. 5.-Photographs of Petri dishes containing agar inoculated with bacteria

The central rectangular area is the part which was exposed to the ultra-violet radiation. The clear area shows the killing action of the rays transmitted through the thinnest part of the mica screen $\mathrm{N}_{3}$. Intensity, $\mathrm{I} \div 20$. Exposure, $T=8$ and $\mathrm{I} 6 \mathrm{~min}$. 
transmission is increased only by 5 to 2 per cent, respectively. This difference in transmission greatly accelerates the germicidal action through the thinner film, which would hardly be expected if it were merely a question of total energy increase. For, it so happens that a 2 to 5 per cent increase in energy value of the radiation of wave lengths 3 I 3 to $436 \mathrm{~m} \mu$ gives practically the same integrated value as a 30 to 50 per cent increase in the spectral radiation of wave lengths 240 to $305 \mathrm{~m} \mu$ (see Table $\mathrm{I}, 0.47$ against $0.34 \mathrm{~cm}$ deflection). Moreover, as mentioned in the discussion of the "Spectral range of abiotic action" using the screen of glass, curve 4, in Figure 4, which transmits only the spectral lines at 3 I 3

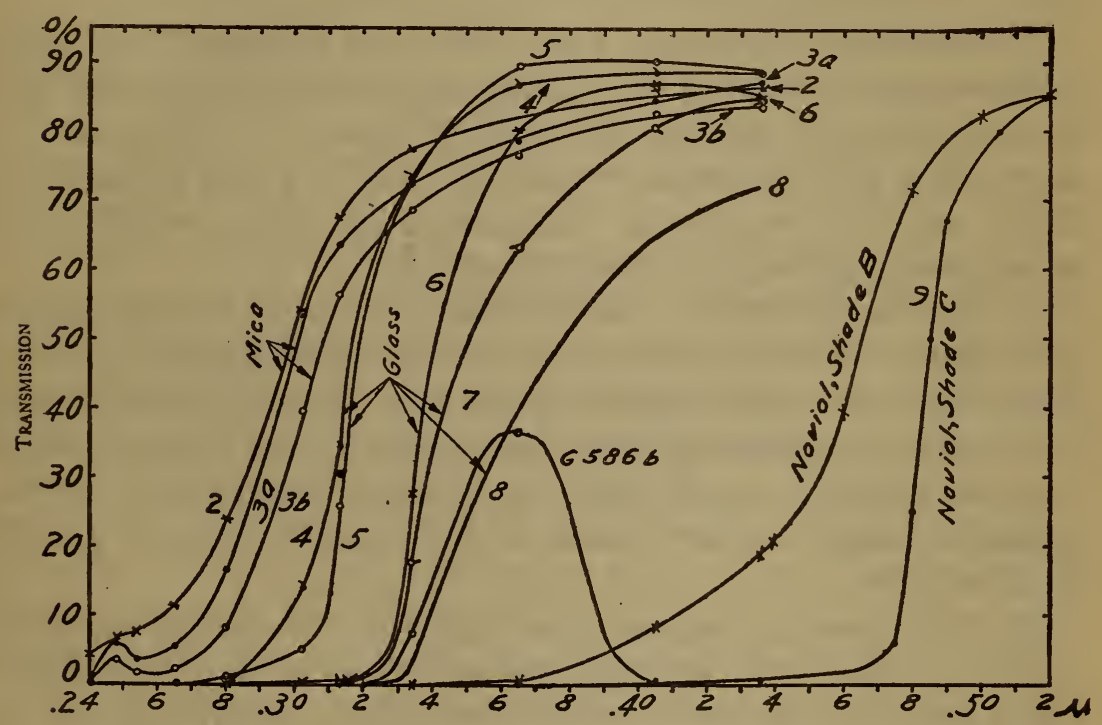

FIG. 4.-Spectral transmission curves of the screens used in testing bactericidal action

to $365 \mathrm{~m} \mu$, and increasing the intensity by changing the distance, do not accelerate the germicidal action in a manner comparable with that obtained by using the mica screens. (See a further discussion under the section on "The energy required to kill a bacterium.")

The present procedure may, therefore, be considered subtractive, in that all radiations of wave lengths less than about $230 \mathrm{~m} \mu$ are absorbed, and additive for the spectral region of 240 to $305 \mathrm{~m} \mu$, without greatly affecting the region of 3 I 3 to $436 \mathrm{~m} \mu$, by using mica screens of different thicknesses.

The manner of selecting screens of suitable thickness was by projecting the ultra-violet spectrum upon a fluorescent surface, 
prepared as described elsewhere, ${ }^{19}$ and noting where fluorescence ceased when the mica screen was interposed before the spectrometer slit.

The uniformity of the thickness of the mica screen was observable by means of the interference colors produced by the light from the mercury lamp. The difference in germicidal action as the result of a difference in thickness of the screen is also observable in the incubated bacterium cultures after exposure to the mercury lamp (see fig. 5). This is well illustrated in the righthand (I6-minute) exposure where the almost complete killing action coincides closely with the irregular cleavage line in the mica.

These screens (size about 4 by $5 \mathrm{~cm}$ ) were mounted upon thick cardboard and numbered $N_{2}, N_{3}$, etc., as shown in the photographs, or No. 2, No. 3, etc., as recorded in Table I. The screen $N_{1}$ represented the unobstructed opening ( 4 by $4.5 \mathrm{~cm}$ ) in the cardboard used in determining the germicidal action of the total radiation emanating from the mercury arc.

As may be noticed in the illustration (fig. 5), the cardboard shielded part of the bacterium culture (the white specks) from the ultra-violet rays, thus providing an easy means of determining the density and uniformity of distribution of the culture, which was not exposed to the light, and, hence, inferentially of the probable density of the culture in the central, exposed part of the Petri dish.

(a) Data on the Transmission Screens.-Referring to Figure 4 , curve 2 depicts the spectral transmission of screen No. 2 which was a plate of mica, o.oI $\mathrm{mm}$ in thickness. Curves $3 a$ and $3 b$ give the transmission of screen No. 3 , which was a plate of mica having a maximum thickness of about $0.02 \mathrm{~mm}$. The two areas $3 a$ and $3 b$ of this plate of mica differed but little in thickness, nevertheless there is a marked difference in the bactericidal action. These two screens were split from thick mica plates which differed considerably in color, hence in ultra-violet absorption, as affected by the coloring matter in the crystal.

Curves 4 and 5 give the spectral transmission of screens Nos. 4 and 5 of thin, white crown glass, having a thickness of 0.915 and I.25 mm, respectively.

Curves 6 and 7 depict the spectral transmission of plate window glass, having a thickness of 1.93 and $3.02 \mathrm{~mm}$, respec-

10 Methods and apparatus in spectroradiometry, Coblentz, Jour. Opt. Soc. Amer., 7, p. 451; 1923. 
tively. Viewed edgewise these two samples had a marked greenish tint.

Screen No. 8 was made of two superimposed pieces of window glass, cut from the same plate as screen No. 7 , the total thickness being $6.04 \mathrm{~mm}$. These three screens were used in an attempt to establish the long wave-length limit of bactericidal action. The transmission of the $313 \mathrm{~m} \mu$ line through these screens, Nos. 6,7 , and 8 , was $0.4,0.2$, and 0.04 per cent, respectively.

Photographs were made of the quartz mercury arc spectrum, through these screens by Dr. W. F. Meggers, of the spectroscopy section of this bureau. Spectrograms of exposures, some of which were sufficiently prolonged to fog the plate, showed the $3 \mathrm{I} 3 \mathrm{~m} \mu$ line through screen No. 6 ( $\mathrm{Tr} .=0.4$ per cent), but showed no impression of this line through screen No. 7 ( $\mathrm{Tr} .=0.2$ per cent).

In Figure 4, curve 9 illustrates the spectral transmission of a yeliow, shade $C$, Corning Noviol glass screen, having a thickness of $\mathrm{r} .97 \mathrm{~mm}$.

In Figure 4 is given the transmission of a Corning glass, $\mathrm{G}_{5} 86 \mathrm{~J}$ (thickness $2.78 \mathrm{~mm}$ ), which has a high transmission for the 365 $\mathrm{m} \mu$ line and an immeasurably small transmission for the 3 I $3 \mathrm{~m} \mu$ line. Spectrograms of to minutes exposure showed only a faint impression of the $3 \mathrm{r} 3 \mathrm{~m} \mu$ line upon the photographic plate.

The quartz mercury arc emits practically no radiation of wave lengths lying between 436 and $546 \mathrm{~m} \mu$. Hence, the shade $C$ Noviol glass establishes the long wave-length limit at $436 \mathrm{~m} \mu$. As will be shown presently, the abiotic action of the radiation of wave lengths 365 to $436 \mathrm{~m} \mu$ is very slow in spite of their high intersity. Hence, there is no need of including radiation of longer wave lengths in this investigation.

\section{CALIBRATION OF THE RADIATION INTENSITY}

One important reason for undertaking the present investigation was to attempt to place the germicidal action of ultra-violet radiation on a quantitative radiometric basis. While there can be no longer any doubt that the greatest abiotic action is produced by ultra-violet radiation of very short wave lengths, as noted in the introductory part of this paper there is need of information concerning the energy relations involved in germicidal action in different parts of the ultra-violet spectrum.

Photographs of the emission spectrum of the quartz mercury arc burner (see fig. 3) show that the ultra-violet spectrum consists $832^{\circ}-24-3$ 
of a number of sharp emission lines superposed upon a weak, continuous background. ${ }^{20}$

The distribution of intensities in these (radiometrically measurable) spectral lines extending from 220 to $436 \mathrm{~m} \mu$, when the burner was operated on 320 watts (8o volts, 4 amperes) is given in Figure 2. The relative intensities of the spectral lines vary with the power input, as shown in a previous paper. ${ }^{21}$ In the present research the potential applied to the burner was held constant from day to day at 79 to 80 volts, or close to 320 watts.

In the quartz-mercury arc the intensity of the continuous spectrum is weak in comparison with the intense emission lines, which are widely separated and, hence, easily measured radiometrically. Hence one can easily calculate the intensity of the radiation stimulus for a given spectral region and compare it with the observed value, as obtained through the various transmission screens. This is accomplished in the following manner: First, an estimate is obtained of the total energy in the whole spectral region by taking the sum of the galvanometer deflections of all the measurable emission lines (see fig. 2) extending from 220 $\mathrm{m} \mu$ to, and including, $436 \mathrm{~m} \mu$. Similarly the amount transmitted through the various screens is obtained by multiplying the intensities of these emission lines by the spectral transmissions, given in Figure 4, and taking the sum of the transmitted intensities. The ratio of these two summations gives the per cent transmission of the radiation of wave lengths less than (and including) $436 \mathrm{~m} \mu$, which, for the present investigation, is taken to be the long wave-length limit of germicidal action. Experimentally this long wave-length limit was obtained by using a shade $C$ Noviol glass screen (see fig. 4), which is opaque to wave lengths less than $405 \mathrm{~m} \mu$, and transmitted only 0.3 per cent of the mercury line at $436 \mathrm{~m} \mu$.

The amount transmitted through the various screens was determined experimentally in the following manner: A thermopile, covered with a I $\mathrm{cm}$ cell of water, was used as a radio-meter, as in previous measurements of this type. ${ }^{22}$ It was placed at a fixed distance ( $16 \mathrm{~cm}$ ) from the burner and the galvanometer deflection (26 cm; see Table I) was noted; also the galvanometer

${ }^{20}$ Souder, Phys. Rov. (2), 8, p. 316; x916. In this paper as well as in one by Koppius, Phys. Rev. (2), 18, p. 450; 1922, energy measurements are given of the intensities of the spectral lines. The relative intensities of these lines depend, of course, upon the power-input, and, hence, the data are not necessarily comparable with the measurements given in the present paper.

21 Coblentz, Amer. Jr. Electrotherapeutics and Radiology, 39, p. 405; 192x.

22 B. S. Sci. Paper, No. 330. 
deflection $(9 \mathrm{~cm})$ when the shade $C$ Noviol glass was interposed. The difference in the galvanometer deflections $(17 \mathrm{~cm})$ is a measure of the ultra-violet radiation, extending from 170 to $436 \mathrm{~m} \mu$. Using the glass screen No. 6 (see fig. 4) the galvanometer deflection was $17.8 \mathrm{~cm}$. The deflection for wave lengths 320 to $436 \mathrm{~m} \mu$ is, therefore, $8.8 \mathrm{~cm}$. Similarly, a deflection of $12.5 \mathrm{~cm}$ was obtained for the ultra-violet transmission through glass screen No. 2. The ratio of the deflections for these two screens, No. $6 \div$ No. 2, gives the transmission (7I per cent) of the radiation of wave lengths between 220 and $436 \mathrm{~m} \mu$. The calculated value is 72 per cent. Similar data, for other spectral regions are given in Table I, showing the close agreement between the observed and the calculated values of the radiation transmitted through (or excluded by) these various screens. The fact that there is such a close agreement between the calculated values using the dispersed radiation, and the observed values, using the undispersed radiation, seems to indicate that the energy value of the radiation of wave lengths less than $220 \mathrm{~m} \mu$ (which was neglected in the calculations, because it was absorbed by the spectroscope, though present in the undispersed radiation) is extremely small. Nevertheless, the radiation of wave lengths less than $220 \mathrm{~m} \mu$ has a powerful bactericidal action.

To recapitulate, the foregoing demonstration of the close agreement between the calculated and the observed transmissions serves two purposes, viz, (I) it shows the small energy value of the radiation of wave lengths less than $220 \mathrm{~m} \mu$, emitted by the quartz-mercury arc, which radiation is quite immeasurable because of absorption in a quartz spectroradiometer, and (2) it shows the reliability of the transmission data which were obtained only by calculation.

An estimate of the radiation intensity in absolute value was obtained by calibrating the galvanometer deflection, by exposing the thermopile to a standard of radiation. ${ }^{23}$ In this manner it was determined that a galvanometer deflection of $\mathrm{I} \mathrm{cm}=5 \times \mathrm{rO}^{-6}$ watt per square millimeter and that the radiant flux of wave lengths I 70 to $\mathrm{I}, 400 \mathrm{~m} \mu$ was $I_{\circ}=0.00013$ watt per square millimeter at a distance of $16 \mathrm{~cm}$ from the burner. This represents the full intensity, $I_{0}$, used in these experiments. Intensities of $\mathrm{I} / \mathrm{IO}, \mathrm{I} / 2 \mathrm{O}$, $\mathrm{I} / 35$, and $\mathrm{I} / 50$ were also used, as already described.

${ }^{23}$ B. S. Bull., 11, p. 87 ; 1914. 
This value is in exact agreement with previous measurements ${ }^{24}$ in which it was found that the radiant flux of wave lengths less than $\mathrm{I}, 400 \mathrm{~m} \mu$ at $\mathrm{I} 6 \mathrm{~cm}$ from a 220 -volt burner was $0.00044 \mathrm{watt}$ per square millimeter. This was 3.4 times the average intensity of several I Io-volt burners, or 0.00013 watt per square millimeter for the Iro-volt burner. It is to be understood, of course, that only a small proportion of this energy is of wave lengths which have any abiotic action. This question will be discussed in a subsequent section in which an estimate will be obtained of the energy required for killing cultures of bacteria.

TABLE 1.-Data on the Energy Transmitted and Absorbed (Including the Part Reflected; 9 per cent) by the Various Screens Used in Bactericidal Tests. A Deflection of $1 \mathrm{~cm}=5 \times 10^{-6}$ watt per $\mathrm{mm}^{2}$ at a distance of $16 \mathrm{~cm}$ from the burner

\begin{tabular}{|c|c|c|c|c|c|c|c|c|}
\hline \multirow[b]{2}{*}{ Screen } & \multirow{2}{*}{$\begin{array}{c}\text { Spectral } \\
\text { limits of } \\
\text { transmitted } \\
\text { radiation }\end{array}$} & \multicolumn{2}{|c|}{$\underset{\text { mitted }}{\text { Radiation trans- }}$} & \multirow{2}{*}{\multicolumn{2}{|c|}{ Screen }} & \multirow{2}{*}{$\begin{array}{l}\text { Spectral } \\
\text { limits of } \\
\text { absorbed } \\
\text { radiation }\end{array}$} & \multicolumn{2}{|c|}{$\begin{array}{c}\text { Radiation } \\
\text { absorbed }=a \\
\text { transmitted }=t\end{array}$} \\
\hline & & $\begin{array}{c}\text { Gal- } \\
\text { vanom- } \\
\text { eter } \\
\text { deflec- } \\
\text { tion }\end{array}$ & $\begin{array}{l}\text { Gal- } \\
\text { vanom- } \\
\text { eter } \\
\text { correc- } \\
\text { tion for } \\
\text { reflec- } \\
\text { tion }\end{array}$ & & & & $\begin{array}{l}\text { Gal- } \\
\text { vanom- } \\
\text { eter } \\
\text { deflec- } \\
\text { tion }\end{array}$ & $\begin{array}{c}\text { Per } \\
\text { cent } \\
\text { of total } \\
\text { to } 436 \mathrm{~m} \mu\end{array}$ \\
\hline 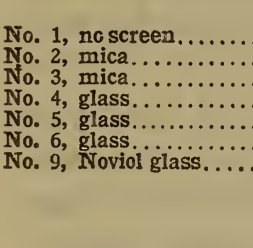 & $\begin{array}{c}\mathrm{m} \mu \\
170 \text { to } 1,400 \ldots \\
220 \text { to } 1,400 \ldots \\
240 \text { to } 1,400 \ldots \\
280 \text { to } 1,400 \ldots \\
280 \text { to } 1,400 \ldots \\
320 \text { to } 1,400 \ldots \\
436 \text { to } 1,400 \ldots\end{array}$ & $\begin{array}{l}\mathrm{cm} \\
26.0 \\
21.5 \\
20.6 \\
19.8 \\
19.4 \\
17.8 \\
9.0\end{array}$ & $\begin{array}{r}26.0 \\
23.4 \\
22.4 \\
21.6 \\
21.2 \\
19.4 \\
9.8\end{array}$ & \multicolumn{2}{|c|}{$\begin{array}{l}\text { No. } 1-N 0.9 \ldots \\
\text { No. } 1-N 0.2 \ldots \ldots \\
\text { No. } 1-N 0.4 \ldots \\
\text { No. } 1-N 0.5 \ldots \\
\text { No. } 2-N 0.4 \ldots \\
\text { No. } 3 \mathrm{a} \ldots \ldots \ldots \\
\text { No. } 3 \mathrm{~b} \ldots \ldots \ldots \\
\text { No. } 3 \mathrm{a}-\mathrm{No} .3 \mathrm{~b} . \\
\text { No. } 3 \mathrm{a}-\mathrm{No} .3 \mathrm{~b} . \\
\text { No. } 2-\text { No. } 5 \ldots .\end{array}$} & $\begin{array}{c}\text { m } \mu \\
170 \text { to } 436 \ldots \\
170 \text { to } 220 \ldots \\
170 \text { to } 280 \ldots \\
170 \text { to } 280 \ldots \\
220 \text { to } 280 . \\
240 \text { to } 305 . \\
313 \text { to } 436 . . \\
240 \text { to } 305 . . \\
313 \text { to } 436 . \\
220 \text { to } 305 .\end{array}$ & $\begin{array}{c}\mathrm{cm} \\
a 16.2 \\
a 2.6 \\
a 4.4 \\
a 4.8 \\
a 1.7 \\
1.2 \\
10.4 \\
0.34 \\
.47 \\
2.2\end{array}$ & $\begin{array}{r}100.0 a \\
16.1 a \\
27.1 a \\
29.6 a \\
10.5 a \\
10.2 t \\
89.8 t \\
28.3 t \\
4.5 t \\
\ldots \ldots . . .\end{array}$ \\
\hline \multirow{2}{*}{\multicolumn{2}{|c|}{ Screen }} & \multirow{2}{*}{$\begin{array}{c}\text { Spectral } \\
\text { limits of } \\
\text { transmitted } \\
\text { radiation }\end{array}$} & \multirow{2}{*}{$\begin{array}{l}\text { Gal- } \\
\text { vanom- } \\
\text { eter } \\
\text { deflec- } \\
\text { tion }\end{array}$} & \multirow{2}{*}{$\begin{array}{l}\text { Per cent } \\
\text { of total }\end{array}$} & \multirow{2}{*}{\multicolumn{2}{|c|}{ Screen }} & \multicolumn{2}{|c|}{ Transmission } \\
\hline & & & & & & & Observed & $\begin{array}{l}\text { Calcu- } \\
\text { lated }\end{array}$ \\
\hline 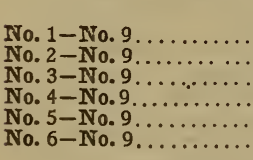 & & $\begin{array}{l}\operatorname{m} \mu \\
\text { to } 436 \ldots \\
\text { to } 436 \ldots \\
\text { to } 436 \ldots \\
\text { to } 436 \ldots \\
\text { to } 436 \ldots \\
\text { to } 436 \ldots\end{array}$ & $\begin{array}{l}\mathrm{cm} \\
17.0 \\
12.5 \\
11.6 \\
10.8 \\
10.4 \\
8.8\end{array}$ & $\begin{array}{r}100.0 \\
74.2 \\
68.3 \\
63.6 \\
61.2 \\
51.8\end{array}$ & $\begin{array}{l}\text { No. } 3 \\
\text { No. } 5 \\
\text { No. } 6 \\
\text { No. } 6 \\
\text { No. } 6\end{array}$ & $\begin{array}{l}3 \div N o .2 \ldots \\
5 \div N 0.3 \ldots \\
5 \div N 0.5 . . \\
5 \div N o .2 . . \\
5 \div N 0.3 \ldots\end{array}$ & $\begin{array}{l}0.92 \\
.90 \\
.85 \\
.71 \\
.77 \\
77 .\end{array}$ & $\begin{array}{r}0.92 \\
.92 \\
.85 \\
.72 \\
.78\end{array}$ \\
\hline
\end{tabular}

a Corrected for reflection.

\section{SPECTRAL TRANSMISSION OF SOME CULTURE MEDIA AND AMINO ACIDS}

In the introductory part of this paper experimental data were cited showing that organisms having cell walls which are highly opaque to ultra-violet radiation are very resistant to the lethal action of these rays.

${ }^{24}$ B. S. Sci. Paper No. 330, Tables 6 and 7. 
The absorptivity of the culture medium must also be considered. In our tests, using the Petri dishes, the bacterial cultures were sown on the surface of the nutriment agar, and, hence, the depth of penetration of the rays into the culture medium is of secondary importance.

However, for certain determinations it would be desirable to use suspensions of bacteria in liquid media, in which case the depth of penetration of the abiotic rays into the medium is an important factor in the killing action. Our preliminary experiments on the germicidal action of ultra-violet radiation on suspensions of $B$. coli in distilled water showed appreciable experimental error, owing to considerable dying of the bacteria in the stock suspension before a large series of exposures could be completed.

An examination was, therefore, made of the spectral transmission of certain nutrient solutions to determine their transparency, and, hence, their suitability in studying the abiotic action of ultraviolet radiation.

The investigations of Kreusler ${ }^{25}$ and of others show that the spectral transmission of pure (freshly distilled) water is high throughout the range from 200 to $300 \mathrm{~m} \mu$. After standing for a short time in a soft-glass container, enough glass is dissolved to reduce the spectral transmission; for example, using a cell $\mathrm{r} .7 \mathrm{~cm}$. in thickness, Kreusler observed that at $200 \mathrm{~m} \mu$ the absorption of fresh water was 3 r.8 per cent, and, after standing in a glass bottle for half a day, the absorption increased to 70.6 per cent. By storing the water in hard-glass containers there was little change in the absorption.

(a) WATER.-In connection with the present investigation, the spectral transmission was determined immediately after making the bactericidal tests of distilled water suspensions of $B$. coli, and of similar suspensions in water containing a small proportion of nutrient material; for example, I/40 and I/500 dilutions of standard beef-peptone bouillon and also a I per cent solution of peptone. In Figure 6 is illustrated, by means of the circles $(\bigcirc \bigcirc \bigcirc)$ the spectral transmission (uncorrected for reflection and absorption of the quartz windows) of a $\mathrm{I} \mathrm{cm}$ layer of water, containing about 600,000 B. coli per cubic centimeter.

From this it may be noted that the water suspension of $B$. coli absorbs but little of the abiotic rays. 
(b) BouILLON.-In Figure 6 the circles $(\bigcirc \bigcirc \bigcirc)$ depict the spectral transmission of a I cm cell containing beef-peptone bouillon, the concentration being $\mathrm{I} / 4 \mathrm{O}$ of the standard strength ( $3 \mathrm{~g}$ beef extract, $10 \mathrm{~g}$ peptone, and $5 \mathrm{~g}$ sodium chloride per $\mathrm{I}, 000 \mathrm{~cm}^{3}$ distilled water).

In this same illustration the crosses ( $\mathrm{x} \times \mathrm{x}$ ) depict the spectral transmission of a $\mathrm{r} / 500$ solution of bouillon. In the weaker concentration the absorption band at $250 \mathrm{~m} \mu$ is almost eliminated, thus permitting the abiotic rays to penetrate a water suspension

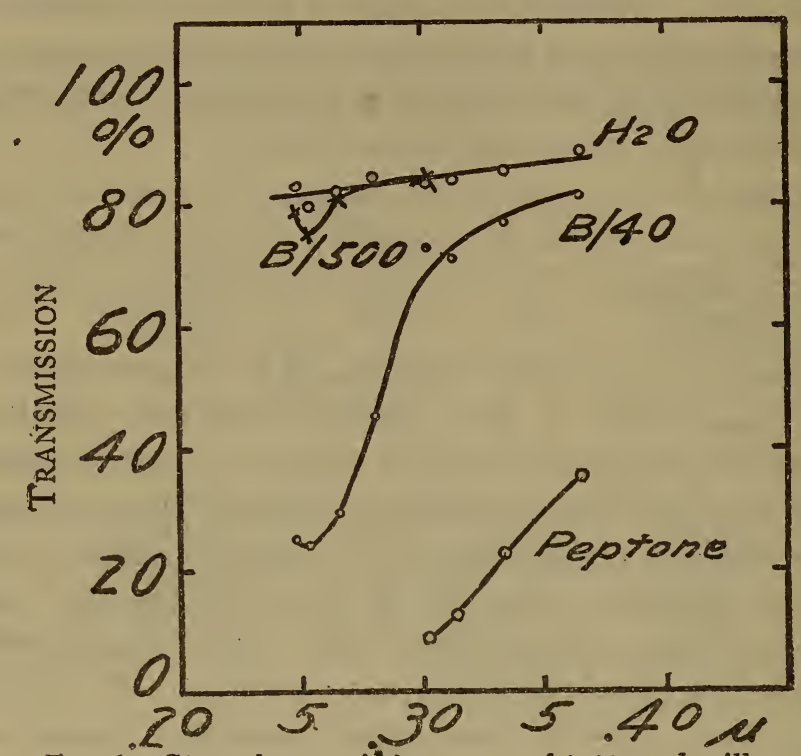

FIG. 6.-Spectral transmission curves of peptone, bouillon, and water

of bacteria with practically undiminished intensity relative to the more dense solution.

(c) PEPTONE.-In Figure 6 is illustrated the spectral transmission through a I cm thickness of water containing $0.0 \mathrm{I} \mathrm{g} / \mathrm{cm}^{3}$ of peptone, and about $600,000 \mathrm{~B}$. coli per cubic centimeter. This nutrient material developed a deep-brown color during sterilization and has a high absorption of the abiotic rays, which, as will be shown in a subsequent part of this paper, greatly retards the killing action.

From this it appears that, because of their great opacity to ultra-violet radiation, standard strength solutions of beef bouillon and of peptone are optically unsuitable as liquid nutrient media in germicidal tests. 
(d) Tyrosin and Phenylalanin.-These amino acids are supposed to be some of the absorbing substances forming the cell walls of bacteria and protozoa. According to Kober ${ }^{26}$ a water solution of tyrosin has an absorption band extending from 248 to $297 \mathrm{~m} \mu$, and phenylalanin has a similar band extending from 236 to $27 \mathrm{I} \mathrm{m} \mu$. Hence, some investigators have assumed that ultraviolet radiation of this spectral region should be most toxic to protoplasm. No quantitative spectral transmission measurements were made in the present investigation. However (in connection with the use of these materials as transmission screens, to be discussed presently), by projecting the ultra-violet spectrum upon a fluorescent screen ${ }^{27}$ it was found that dilute solutions of these substances have a narrow absorption band comprised within the limits established by Kober, the maximum absorption being in the region of 270 to $280 \mathrm{~m} \mu$.

\section{BIOLOGICAL MATERIAL AND METHODS}

Bacterium coli communis, recently isolated from human feces, was used as a test organism, largely because this species has been included in practically all experiments dealing with the bactericidal effect of ultra-violet light, and despite the fact that $B$. coli has given evidence of showing a certain amount of irregularity in its reaction to the radiation, which may have been due to clumping or to individual differences in resistivity. The cultures used were on standard beef-peptone agar and were grown for three days at room temperature of about $22^{\circ} \mathrm{C}$. A loop of the abundant surface growth was transferred to sterile distilled water, using the proper dilution to give the desired thickness in the final sowing of the organism. The suspension was atomized as uniformly as possible over the surface of a Petri dish containing hardened sterile beef-peptone agar made up to be rather firm ( 2 per cent agar shreds). It was found advantageous to direct the nozzle of the atomizer upward and to hold the Petri dish in an inverted position some $30 \mathrm{~cm}$ away so as to avoid large droplets. With care in judging the amount of surface growth transferred on the loop, and the amount of suspension atomized over the surface of the plate, fairly uniform sowings were secured. As soon as practicable after preparation the exposures to the ultra-violet light were made. In a large series with long exposures one or two hours sometimes necessarily intervened in the case of particular plates,

26 Kober, Jour. Biol. Chem., V, 22, p. 433; rgI5.

${ }^{27}$ Coblentz, Jour. Opt. Soc. Amer. and Rev. Sci. Insts., 7, p. 45 ; r923. 
but check plates did not show any serious error from this delay. However, when making exposures using long wave lengths $(365 \mathrm{~m} \mu)$ after the inoculated plates had stood for four hours, a noticeable retardation in the killing action was observed. Exposed plates were held three or four days at room temperature before records were made. The counts were made under a reading glass magnifying four diameters.

This method has the advantage of exposing the organisms in a thin layer very uniformly to the action of the ultra-violet rays and of permitting the rapid handling of a large series of exposures. It is particularly useful for determining the time for practically complete killing. It is not an accurate method for determining the rate of numerical decrease during the earlier stages of killing, for the reason that each droplet of liquid in thick seeding contains more than one organism, and no decrease in number of colonies is evidenced until the killing has become complete for many of the droplets. If the droplets could be made to carry uniformly one organism each, this method would then be satisfactory for determining the rate of killing from the beginning of the lethal effect.

The method of plating out from water suspensions of the organism exposed for different periods is the ideal one for determining the rate of bactericidal action. Our results from the use of this method, as has been heretofore mentioned, have seemed to be influenced by several complicating factors, among them the difficulty of maintaining a constant number of organisms in the stock suspension during the progress of an extended test, and it must be improved in details before the maximum accuracy in results is obtained.

The method used by some previous investigators of securing complete sterilization of a suspension of bacteria in a nutrient solution is open to the threefold objection, (I) that the medium itself may act as a highly protective screen, (2) that considerable irregularity may result from the chance survival of a few organisms for abnormally long periods, and (3) that the progressive rate of killing can not be determined.

\section{EXPERIMENTAL DATA}

\section{EFFECT OF ULTRA-VIOLET LIGHT UPON THE CULTURE MEDIUM}

In the introductory part of this paper the experiments of Browning and Russ were cited, showing that the ultra-violet light had no effect upon the uninoculated (agar) culture medium. 
They found no difference in the density of growth of the organisms over the portions of the agar which were irradiated and nonirradiated before inoculation.

Similar results were obtained in the present investigation for the intensities and times requisite for complete killing. However, when using very high radiation intensities it was found that the ultra-violet light had sufficient effect upon the uninoculated beef-peptone agar, so that, after inoculation, there was considerable mortality of the $B$. coli.

The experimental procedure was to hold the Petri dish of uninoculated beef-peptone agar for various times from 4 to 64 seconds at a distance of about $5 \mathrm{~cm}$ from the mercury arc burner. The intensity was, therefore, about Io times that used in our regular experiments. The dishes were then atomized at once ( $T=O$ hours) with a culture of $B$. coli and incubated for four days.

The results are shown in Figure 7 , in which No. I and the lefthand side of No. 2 are photographs of parts of the unexposed control dishes. The density of the inoculation (the white flecks) shows the thickness of the sowing of $B$. coli.

The right-hand side of dish No. 2 and the whole of dish No. 3 were exposed to ultra-violet radiation before inoculation. This caused a high mortality or inhibition of growth of the $B$. coli. The white flecks are a measure of the number of bacteria which survived. No. 2 is especially conspicuous in showing the effect of the ultraviolet radiation upon the culture medium.

It is relevant to add that this was first noticed on some Petri dishes of uninoculated agar which had become contaminated with mold spores. As a quick means of killing these spores, the dishes were exposed to intense ultra-violet radiation before inoculation. It was then found that while this is a ready and effective means of disinfecting the culture medium, it had a disastrous effect upon the subsequent cultures. Aside from establishing this fact no attempt was made to determine the exact cause of this failure to grow or how long after exposure this deleterious action continued in the culture medium.

In conclusion it is important to emphasize that our results, in general, are in agreement with those of recent investigators, showing that the killing of bacteria by ultra-violet rays is not due to the small amounts of toxic chemical substances that may be produced by the action of the rays on the water or other medium. 
Our control tests show that this holds true for the standard beef-peptone agar used in the work, for the periods and intensities of exposure necessary to secure complete killing effect, and that changes in the culture media are a negligible factor in the killing effects observed. However, when the Petri dishes containing the beef-peptone agar were given excessive exposures to the ultraviolet, either by greatly prolonging the time of preexposures or by bringing the dishes very close to the lamp and thus increasing the intensity and possibly the spectral range of the radiation, it was found, as just described, that subsequent seeding on the surface of the preexposed agar gave no growth or only a small number of colonies as compared with portions of the same dish that had been shielded from exposure to the radiation. That a drying or cooking effect of the agar surface caused by heat radiation was not responsible for the observed result was shown by the fact that agar exposed to similar intensities of heat radiated from a flatiron supported a normal growth of $B$. coli when later inoculated. A single test of potato agar and of carrot agar, showed no deleterious effect from preexposure to ultra-violet light of the intensities that did so affect beef-peptone agar.

\section{DEATH OF BACTERIA IN DISTILLED WATER}

In most of our work a freshly prepared suspension of bacteria in distilled water (about $500,000 / \mathrm{cm}^{3}$ ) was used for distributing the organism over the surface of the agar. It was observed that the number of bacteria decreased appreciably in the distilled water suspension if it was held several hours at room temperature.

The regular procedure was to atomize the freshly prepared suspension upon all plates of any series, at the beginning of the test. There was no evidence of any important increase or decrease in numbers of colonies on the plates during the time necessarily consumed in making a large series of exposures to ultra-violet radiation. Even if there was some numerical change, due to dying or to natural multiplication, the experimental findings would not be affected, because only part of each Petri dish was exposed to ultraviolet radiation; and the effect of this irradiation was judged by comparison with the adjacent unexposed portion of the same plate.

In Figure 7 the densely flecked photograph No. I shows (part of) a control Petri dish inoculated with a freshly prepared (time in hours $T=O$ ) suspension of $B$. coli in sterile distilled water. Photograph No. 4 shows a similar control dish which was inoculated with this same suspension of $B$. coli after it had been stand- 
ing three hours $(T=3)$ at room temperature. Both of these plates were inoculated under the same conditions.

The lower No. 4 is almost free from the white flecks, which is a measure of the comparative number of colonies of $B$. coli, which had survived after being in the distilled water for three hours.

In Figure 7 the photographs Nos. 5 and 6 show the combined effect of exposure of the agar before inoculation and the effect of using a distilled water suspension of $B$. coli after standing for three hours. These two plates are entirely free from white flecks, showing complete absence of bacterial growth (I) due to some inhibiting or lethal action in the preexposed culture medium, and (2) to the high mortality of the bacteria in the water suspension before inoculation of the culture medium.

These photographs are excellent illustrations of the precautions that are required in making a test in order to be certain that the results obtained are attributable to the causes which are supposed to produce them.

\section{EFFECT OF CONTINUOUS AND INTERMITTENT EXPOSURE}

Considerable experimental data were obtained in order to determine whether there is any difference in the germicidal action of ultra-violet radiation when the total exposure is applied (I) continuously and (2) intermittently with short and long intervals of rest.

The experimental procedure was to expose the Petri dish of thickly inoculated beef-peptone agar to the total, unobstructed radiation (that is, no screen intervened) of the quartz mercury burner. The intensity, $I \div 50$, was selected so as to eliminate errors from too rapid germicidal action relative to variation in shutter speed. The total time of exposure of 48 to 80 seconds was selected, because from previous experience this was found to give good plates which could be counted.

The results (see Table 2) of an examination of the plates showed but little, if any, difference in the density of the growth of bacteria, whatever the method of exposure. From this it would appear that the intermittent exposure does not have a latent effect during the intervals of rest, either in stimulating growth or in continuing the lethal action, and that the lethal effect is additive even with rest periods many times longer than the exposure periods.

It is relevant to add that in the practical applications of ultraviolet light to the killing of microorganisms it would usually be the 
case that a particular organism would not be exposed continuously to the rays, but would be shielded more or less intermittently by other individuals, or perhaps by foreign objects. As already stated, by making continuous exposures of thickly seeded plates for sufficient times to kill 5 o per cent or more of the organisms present, and also by making discontinuous exposures, the summations of which equaled the respective times of continuous exposures (as shown in Table 2), the effects on $B$. coli on the surface of beef-peptone agar were practically the same where the total times of exposure were equal, whether uninterrupted or in parts. This agrees with the conclusion of Bovie ${ }^{28}$ as to the additive effect of Schumann rays.

TABLE 2.-Effect of Continuous and Discontinuous Exposure Upon the Bactericidal Action of Ultra-Violet Rays on $B$. coli

\begin{tabular}{|c|c|c|}
\hline $\begin{array}{c}\text { Total } \\
\text { exposure } \\
\text { (sec- } \\
\text { onds) }\end{array}$ & Method of exposure & $\begin{array}{l}\text { Colonies } \\
\text { surviving }\end{array}$ \\
\hline $\begin{array}{l}64 \\
48 \\
80\end{array}$ & 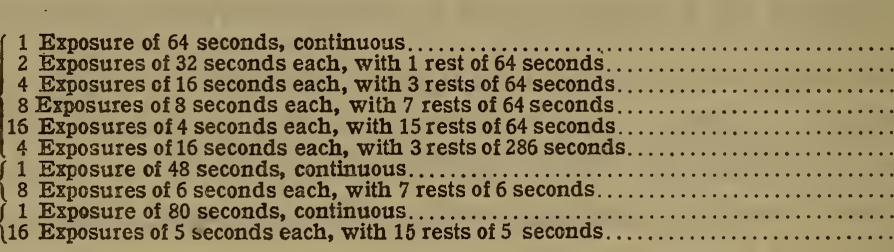 & $\begin{array}{r}\text { Per cm } \\
\text { 2 } \\
83 \\
87 \\
85 \\
75 \\
73 \\
76 \\
130 \\
117 \\
37 \\
39\end{array}$ \\
\hline & Average, check plates, unexposed... & 257 \\
\hline
\end{tabular}

\section{SPECTRAL RANGE OF ABIOTIC ACTION}

The spectral range of wave lengths which have a marked abiotic action is most easily demonstrated by means of the aforementioned transmission screens. A measure of the speed of the lethal action is obtained by counting the surviving colonies of bacteria after various intervals of exposure, through the various screens.

As shown in Table $I$, the energy transmitted by the screens (for example, No. 2 and No. 4) is not sufficiently different to account for the great difference in killing action, which is attributable in part to radiation of short wave lengths absorbed by the screen. As an extreme example we may take No. I-No. 9 (I7 cm deflection) and No.6-No. 9 (8.8 cm deflection). The intensity of the radiation transmitted through the latter is about one-half that available when no screen intervened. Hence, if it were merely a question of intensity, as will be shown presently, by using

${ }^{28}$ Bovie, Bot. Gaz., 61, p. 1; 1916. 
twice the time of exposure through screen No. 6 approximately the same killing action would be obtained as when using no screen. But such is not the case; for an exposure of 15 to 45 minutes through screen No. 6 was required to produce the same killing action upon $B$. coli as was obtained by a one to two second exposure to the unfiltered radiation.

The photographs in Figure 8 are an excellent demonstration of the effect of wave length upon the bactericidal action of ultraviolet radiation. For obtaining the photographs shown in this illustration two intensities, $I \div 50$ and $I \div 35$, were used. When using the intensity $I \div 50$ the Petri dishes were exposed to the unobstructed $\left(N_{1}\right)$ radiation for $T=\mathrm{I}, 2$, and 4 minutes; and when exposed under the mica screen $\left(N_{2}\right)$ the time of exposure was $T=8,16$, and 32 minutes. When using the weaker intensity, $I \div 35$, the exposure time was $0.5, I$, and 2 minutes, respectively, for $N_{1}$, and 4,8 , and 16 minutes, respectively, for $N_{2}$.

It will be understood, of course, that the central rectangular area represents the part of the culture which was exposed to radiation. The surrounding border is part of the Petri dish which was not exposed to radiation, and hence shows the density of the culture.

The number of surviving colonies (the white flecks) in these rectangular areas shows that, when using the mica screen, $N_{2}$, it was necessary to expose the culture about eight times as long in order to obtain the same killing as for the unobstructed radiation, $N_{1}$. The data given in Table I show that the mica screen, $N_{2}$, transmitted 74.2 per cent (obstructed about 26 per cent) of the radiation of wave lengths 220 to $436 \mathrm{~m} \mu$ and about I 6 per cent of the wave lengths I 70 to $220 \mathrm{~m} \mu$. The energy value of these two radiation stimuli $\left(N_{1}\right.$ and $\left.N_{2}\right)$ is so closely (within 26 per cent) the same that, if it were merely a question of intensity, it would not have required an eight times longer exposure to produce the same killing with radiation of wave lengths 220 to $436 \mathrm{~m} \mu$ as when this same radiation included also the wave lengths $\mathrm{I} 7 \mathrm{O}$ to $220 \mathrm{~m} \mu$.

Further experimental evidence is given in the photographic illustrations in Figures Io and I I showing that, in order to obtain the same killing action, at least an eight times longer exposure must be made through the mica screen, $N_{2}$, than when using the complete spectrum, $N_{1}$.

For making these tests a rather heavy suspension of $B$. coli in distilled water was atomized over the surface of beef-peptone 
agar. The unexposed portions of the plate gave an estimate of 200 colonies per square centimeter after three days incubation. Table 3 gives the percentages of colonies developing in the same time on the exposed portion of the plate.

TABLE 3.-Giving the Percentages of Colonies of $B$. coli Which Developed in the Same Time on the Exposed Portion of the Petri Dish

\begin{tabular}{|c|c|c|c|c|c|c|c|c|c|c|c|c|c|c|c|}
\hline \multirow{3}{*}{ Screen } & \multicolumn{15}{|c|}{ Time of exposure } \\
\hline & \multicolumn{6}{|c|}{ Seconds } & \multicolumn{9}{|c|}{ Minutes } \\
\hline & 1 & 2 & 4 & 8 & 15 & 30 & 1 & 2 & 4 & 11 & 16 & 22 & 32 & 45 & 64 \\
\hline 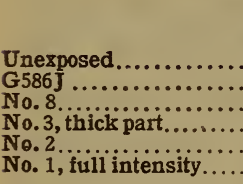 & $\left|\begin{array}{c}\text { Per } \\
\text { cent } \\
100 \\
\cdots \cdots \\
\cdots \cdots \\
\cdots \cdots \\
\cdots \cdots \\
30\end{array}\right|$ & $\begin{array}{c}\text { Per } \\
\text { cent } \\
100 \\
\cdots \cdots\end{array}$ & $\begin{array}{c}\text { Per } \\
\text { cent } \\
100\end{array}$ & \begin{tabular}{c} 
Per \\
cent \\
100 \\
$\cdots \cdots$ \\
\hdashline 100 \\
60
\end{tabular} & $\left|\begin{array}{c}\text { Per } \\
\text { cent } \\
100 \\
\cdots \cdots \\
\cdots 90 \\
1\end{array}\right|$ & $\begin{array}{c}\text { Per } \\
\text { cent } \\
100\end{array}$ & \begin{tabular}{c} 
Per \\
cent \\
100 \\
$\cdots \cdots$ \\
\hdashline .5 \\
.1
\end{tabular} & $\begin{array}{c}\text { Per } \\
\text { cent } \\
100 \\
\cdots \cdots \\
\cdots .5\end{array}$ & $\begin{array}{c}\text { Per } \\
\text { cent } \\
100 \\
100 \\
100 \\
\cdots\end{array}$ & $\begin{array}{c}\text { Per } \\
\text { cent } \\
100 \\
77 \\
64\end{array}$ & $\left|\begin{array}{c}\text { Per } \\
\text { cent } \\
100 \\
6.1 \\
3.9\end{array}\right|$ & $\begin{array}{c}\text { Per } \\
\text { cent } \\
100 \\
2.0 \\
.5\end{array} \mid$ & $\begin{array}{c}\text { Per } \\
\text { cent } \\
100 \\
\cdots \cdots \\
\cdots \cdots \\
\ldots \ldots\end{array} \mid$ & $\begin{array}{c}\text { Per } \\
\text { cent } \\
100 \\
1.6 \\
.4 \\
\cdots \cdots \\
\cdots \cdots\end{array}$ & $\begin{array}{r}\text { Per } \\
\text { cent } \\
100 \\
0 \\
0 \\
\cdots\end{array}$ \\
\hline
\end{tabular}

These data are illustrated in Figure 9. In the lower part of this illustration the curves for screens $N_{1}, N_{2}$, and $N_{3}$ are replotted to a larger scale in order to bring out more clearly the relationships of these curves to each other.

The conclusion to be arrived at from the foregoing experiments is that radiation of wave lengths greater than $305 \mathrm{~m} \mu$ is capable of producing abiotic action. However, the rate at which this can be accomplished, when using only a quartz mercury arc lamp, is only about one-eighth as rapid as obtains with the addition of the shorter wave lengths. The fact that certain experiments cited in the foregoing part of this paper placed the long wavelength limit of bactericidal action at $295 \mathrm{~m} \mu$ is to be ascribed to the very much lower intensities one can obtain in spectrally dispersed radiation and to the fact that the time of exposure was not sufficiently prolonged. If $295 \mathrm{~m} \mu$ were the long wave-length limit, then no germicidal action could be obtained with sunlight, which is contrary to common experience, provided sufficient time is given to obtain the results.

(a) The Long Wave-Length Limit of Abiotic Action.--It seemed desirable to determine, if possible, the longest wave lengths which have a germicidal action. The difficulties involved are great, owing to the fact that, with increasing wave length of the exciting radiation, the rate of abiotic action decreases, and, with the long exposures required to obtain marked killing, it is necessary to guard against germicidal action by heating. 
Scientific Papers of the Bureau of Standards, Vol. 19

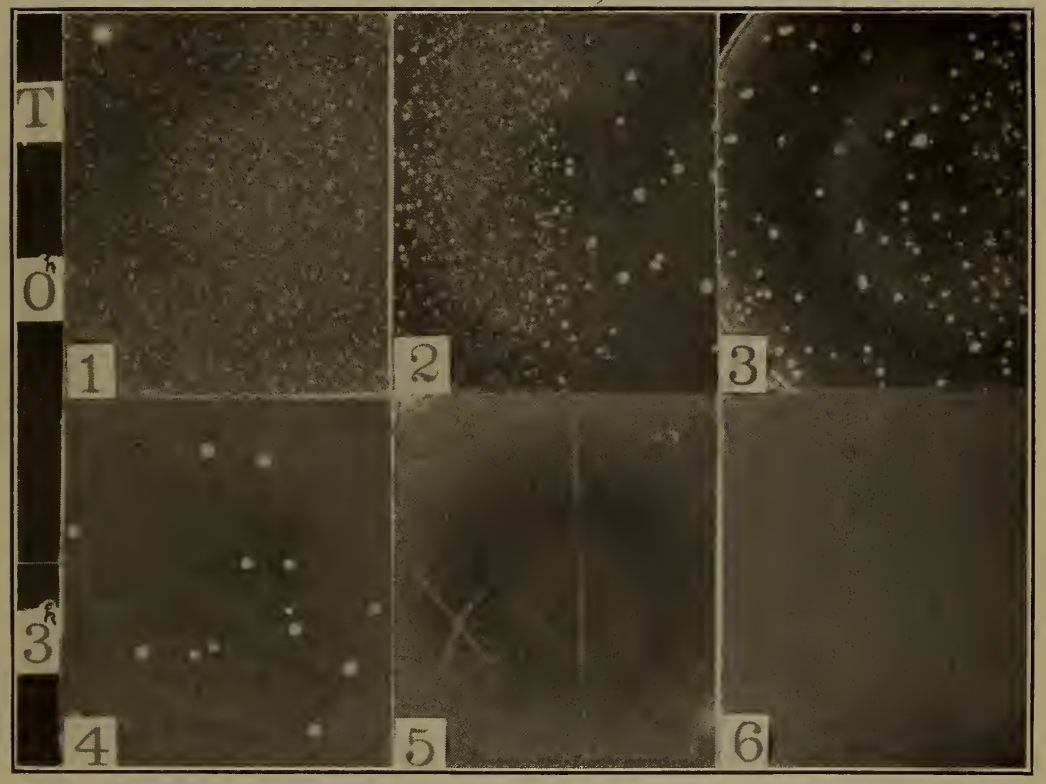

Fig. 7.-Effect of ultra-violel light upon the uninoculated culture medium (agar); also death of bacteria in distilled water. (Time, T, in hours) 
Scientific Papers of the Bureau of Standards, Vol. 19

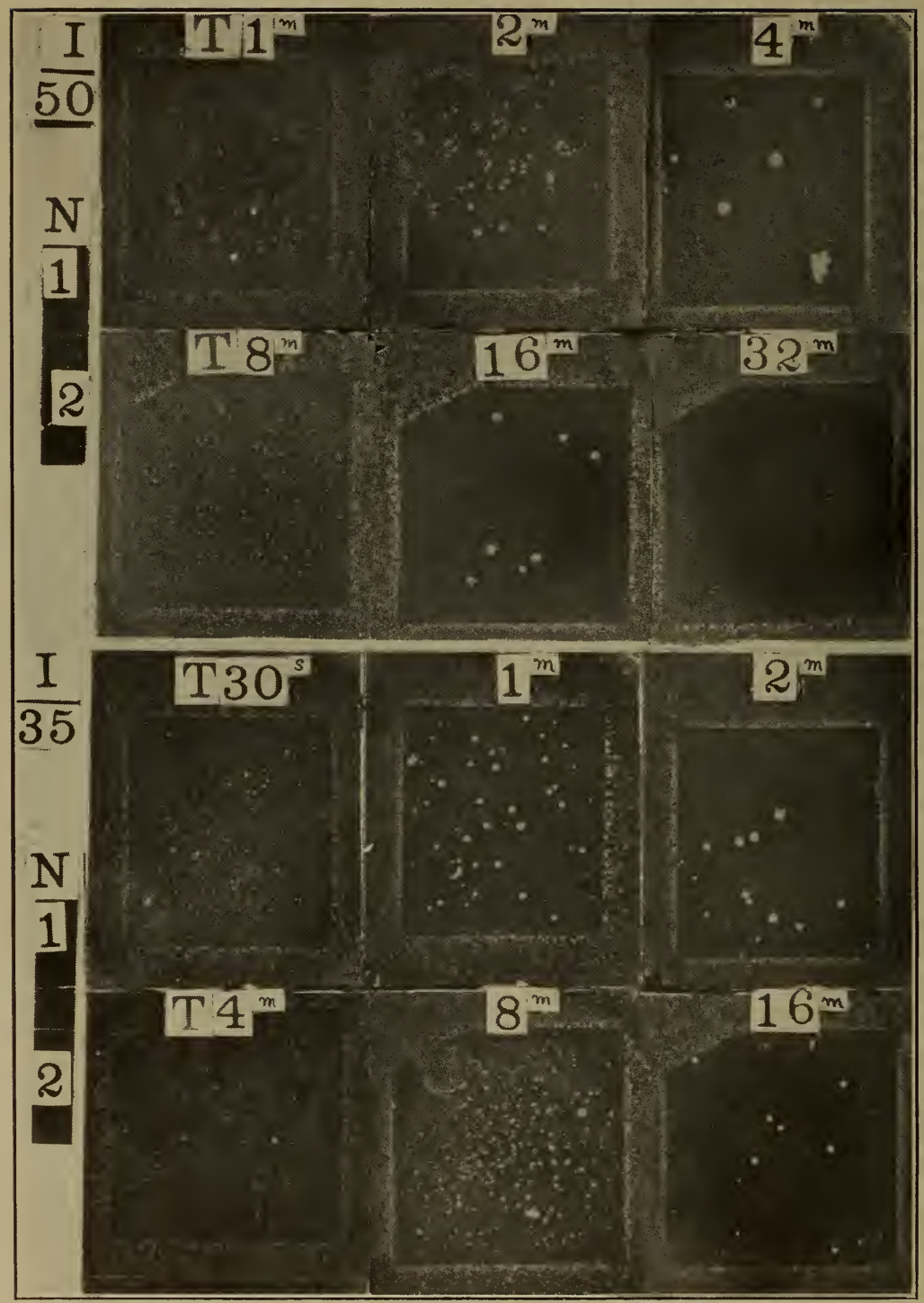

FIG. 8.-Spectral range of abiotic action 
The tests were, therefore, made by mounting two screens (each 3.5 by $4 \mathrm{~cm}$ ) side by side, upon heavy cardboard, having an opening 4 by $7 \mathrm{~cm}$. In addition to the shields depicted in Figure $\mathrm{I}$,

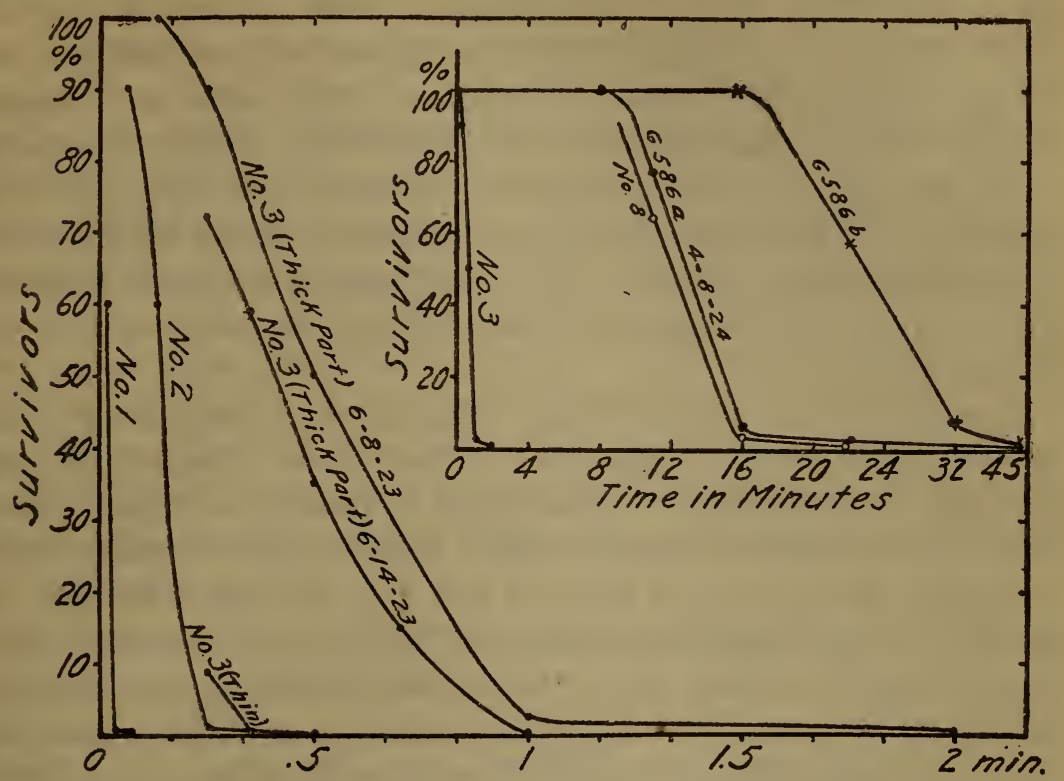

FIG. 9.-Showing percentage of bacteria surviving after exposure for different lengths of time, under various screens

an aluminum reflector was placed directly over these glasses; and, in one series of tests, a thick wooden block intervened between the aluminum shield and the glass plates.

By exposing the inoculated material in the Petri dish simultaneously to the full intensity, $I$, through the two screens, experimental conditions were the same within the inclosure.

The spectral transmissions of these screens are given in Table 4.

TABLE 4.-Per Cent Transmission Through Glass Screens

\begin{tabular}{|c|c|c|c|c|}
\hline \multirow{2}{*}{\multicolumn{2}{|c|}{ Screen }} & \multicolumn{3}{|c|}{ Wave lengths in $\mathrm{m}_{\mu}$} \\
\hline & & 313 & 334 & 365 \\
\hline $\begin{array}{l}\text { No. } 6 \ldots . . . \\
\text { No. } 7 . \ldots \\
\text { No. . } \\
\text { Noviol B. } \\
\text { G586J... }\end{array}$ & & $\begin{array}{l}0.4 \\
.2 \\
.04 \\
0 \\
0\end{array}$ & $\begin{array}{r}27.5 \\
18.0 \\
3.0 \\
0 \\
7.5\end{array}$ & $\begin{array}{l}80 \\
63 \\
40 \\
0.7 \\
36.6\end{array}$ \\
\hline
\end{tabular}

I. Screens Nos. 6 and 7.-Five series of exposures of II to 90 minutes duration gave consistent results, showing the same percentage of killing through these two screens. In the freshly 
inoculated dishes the killing action through No. 6 was a little more rapid than through No. 7 . The time elapsing between inoculation and exposure of the plates had a noticeable effect upon the killing action. For example, after a lapse of four and one-half hours, a 22-minute exposure showed only a small per cent killing whereas, for a freshly inoculated plate, after a 22 -minute exposure there remained only a few surviving colonies of bacteria. It is important to note, however, that in both old and fresh inoculations there was scarcely any difference in the killing action through these two screens. The experimental evidence indicated that wave lengths greater than $3 \mathrm{I} 3 \mathrm{~m} \mu$ predominated in the killing action.

2. Screens Nos. 8 and Noviol.-In the very beginning of this investigation it was found that a three-hour exposure through Corning Noviol, shade $C$, glass failed to produce a killing action. The present tests were made with a shade $B$, Noviol glass, which transmits about 0.6 per cent of the $365 \mathrm{~m} \mu$ line (see fig. 4). Because of its high absorption the Noviol glass becomes much hotter than the clear glass, No. 8, and, hence, if the killing is produced by excessive heating, by infra-red radiation emanating from the heated glass, it should be most marked under the Noviol glass screen.

Using freshly inoculated Petri dishes, complete killing through screen No. 8 was obtained in 45 to 64 minutes, whereas an exposure of two hours showed no killing effect upon the bacteria exposed under the Noviol $B$ screen. From this it may be concluded that the heat radiated from the glass screens did not affect the bacteria, and that radiation of wave lengths greater than $365 \mathrm{~m} \mu$ has only a very slow, if any, germicidal action.

3. Screens Nos. 7 and 8.-The Noviol glass and the clear glass screen No. 8 restrict the abiotic action practically to the 334 and the $365 \mathrm{~m} \mu$ lines.

Using a freshly inoculated dish, complete killing through No. 7 was obtained in 45 minutes while a trace of surviving colonies (0.4 per cent) remained under No. 8. Using dishes which had stood four to five hours after inoculation, an exposure of 90 minutes was required to obtain practically complete killing through screen No. 7 ( 0.3 per cent survivors), while under screen No. 8 there remained 2.5 per cent survivors. The point of interest, however, is that in both cases the killing action through these screens is so closely the same, in spite of the fact that the $313 \mathrm{~m} \mu$ 
line, which might have caused the killing, was practically excluded by screen No. 8 .

No doubt both the 334 and the $365 \mathrm{~m} \mu$ line have an abiotic action. However, when using screen No. 7 , the intensity of the $365 \mathrm{~m} \mu$ line is about 52 times that of the $334 \mathrm{~m} \mu$ line. Using screen No. 8 the intensity of the $365 \mathrm{~m} \mu$ line is 200 times that of the $334 \mathrm{~m} \mu$ line. Although the $365 \mathrm{~m} \mu$ line obtained through No. 8 is relatively less intense than through No. 7 (ratio $40 \div 63$ ) a good killing action is obtained. The slight retardation in killing through No. 8 may be attributed to the decrease in intensity of the $365 \mathrm{~m} \mu$ line. From this analysis it appears that the $365 \mathrm{~m} \mu$ line has an appreciable abiotic action. This conclusion is strengthened by the results obtained with the Noviol glass, which eliminated the $365 \mathrm{~m} \mu$ line and thus prevented abiotic action. In this connection it may be noted injurious effects upon the eye have been noted when wearing glasses which did not completely absorb the $365 \mathrm{~m} \mu$ mercury line.

4. Screens Nos. 8 and G586.--In the foregoing tests the screens transmitted a small amount of the $3 \mathrm{I} 3 \mathrm{~m} \mu$ line, which, in spite of the low intensity, might, perhaps, cause the observed killing action. In a final effort to establish that the $334 \mathrm{~m} \mu$ and the $365 \mathrm{~m} \mu$ lines have a relatively strong abiotic action a series of exposures was made of cultures of bacteria to ultra-violet light, through the highly selective transmission screen $\mathrm{G}_{5} 86$ (see fig. 4), which is exceedingly opaque to the $3 \mathrm{I} 3 \mathrm{~m} \mu$ line. Two samples differing slightly in thickness were used.

Since the intensity of the $313 \mathrm{~m} \mu$ line is immeasurable and the intensity of the $334 \mathrm{~m} \mu$ line, as transmitted through this screen, is only I/8o that of the $365 \mathrm{~m} \mu$ line, it would seem that the latter would contribute the most in the lethal action. As already mentioned, the intensity of the $365 \mathrm{~m} \mu$ line through screen No. 8 is 200 times that of the $334 \mathrm{~m} \mu$ line and 2,000 times that of the $3 \mathrm{r} 3$ $\mathrm{m} \mu$ line.

A series of exposures of II, I6, 22, 32, 45, and 64 minutes duration was made through these two screens (No. 8 and $\mathrm{G}_{586}$ ) mounted side by side, as already described.

Each Petri dish was inoculated with a freshly prepared suspension of $B$. coli just before exposure, thus eliminating aging, and fairly consistent results were obtained from day to day.

The lethal action obtained through screen No. 8 was found to be more rapid than through screen $\mathrm{G}_{5} 86$, as would be expected 
since it transmitted about 8 per cent more of the $365 \mathrm{~m} \mu$ line than the latter. The most important result, however, is that after excluding a possible lethal action of the II $3 \mathrm{~m} \mu$ line, even more thoroughly by means of the screen $\mathrm{G}_{5} 86$ than by screen No. 8, that complete killing was obtained in an hour, as previously observed with screen No. 7. From this it is a reasonable conclusion that, since the intensity of the $365 \mathrm{~m} \mu$ is 80 times that of the $334 \mathrm{~m} \mu$ line, it exerts a relatively powerful lethal action, provided sufficient time is given in making the test. The relative intensities of these two lines are indicated by crosses $(x \mathrm{x})$ in Figure 2.

In the insert of Figure 9 is illustrated the counts of the per cent of surviving bacteria after various times of exposure through these two screens. For the short exposures the per cent of survivors is subject to variation from day to day, owing partly to a small difference in the transmission through these two samples of glass, and also to a probable difference in the suspensions of bacteria. However, all the data are consistent in showing a strong lethal action which effected complete killing in 45 to 64 minutes.

(b) Shielding Action of the Culture Medium.-In a preceding section of this paper the question of suitable culture media was considered, and spectral transmission curves were given of . several media, including peptone (fig. 6), which has a high absorption for the most active germicidal rays. This absorption has a marked retarding effect upon the killing action.

In these tests the suspension of bacteria in the liquid medium (for example, water containing o.or $\mathrm{g} / \mathrm{cm}^{3}$ of peptone) was exposed in open quartz dishes ( 25 by 30 by $30 \mathrm{~mm}$ ) to the ultra-violet rays. The depth of the liquid was about ro $\mathrm{mm}$.

By plating dilution samples that had been exposed for two minutes to an intensity of $I \div 50$, it was found that the numbers surviving out of every $\mathrm{I}, 000$ organisms originally in the several media were as follows: Water, 5 ; for $\mathrm{I} / 500$ bouillon, 34 ; for $\mathrm{I} / 40$ bouillon, 52 ; for I per cent peptone, 832. After an exposure of one minute, the survivors per 1,000 for $1 / 500$ bouillon were 68 , and for I/40 bouillon, 220; and with exposure of one-half minute the survivors were 146 and 740 , respectively. This indicates a much weaker penetration of the ultra-violet rays into the more concentrated bouillon. 
From this it is evident that peptone (or any medium having great opacity to ultra-violet radiation) is optically unsuitable as a nutrient in liquid suspensions of organisms which are to be subjected to germicidal tests. For the medium has the properties of the above-described absorption screens.

(c) Abiotic Action Through Screans of Solutions of Amino Acids.- Harris and Hoyt ${ }^{29}$ in an attempt to determine what substances in bacteria are affected by the action of ultraviolet light, found that solutions of tyrosine and of amino-benzoic acid used as screens detoxicated the ultra-violet light passing through so that bacteria, when dried on cover slips and exposed under these screens, survived exposures up to 16 to 35 times those required to completely kill by the use of unscreened ultra-violet. Since the substances used absorb ultra-violet light of wave lengths 236 to $297 \mathrm{~m} \mu$, these investigators conclude that practically all of the rays toxic for protoplasm should lie within this range. However, from the foregoing tests, using screens of mica and of glass, it is evident that, given sufficient time and intensity, good killing action can be obtained with wave lengths longer than $297 \mathrm{~m} \mu$. Furthermore, the tests with the Schumann rays show that the extremely short wave lengths are also very toxic.

We have tested two of the materials, tyrosine and phenylalanine, discussed by Harris and Hoyt, using beef-peptone agar plates atomized over the surface with a heavy suspension of $B$. coli instead of the less sensitive method with bacteria dried on cover slips. The exposures were made at a distance of $16 \mathrm{~cm}$ $\left(I_{\mathrm{o}}\right)$ from the quartz-mercury arc lamp, through a circular cell 25 $\mathrm{mm}$ in diameter, and $\mathrm{I} \mathrm{cm}$ in thickness with quartz sides. The phenylalanine was used in I per cent aqueous solution, and the tyrosine in a saturated aqueous solution at room temperature of $22^{\circ} \mathrm{C}$., which was approximately 0.04 per cent. Distilled water was used as a check. It was found that Io per cent of the bacteria survived exposure of one second through the water screen; that 56 per cent survived eight seconds, and none survived 30 seconds' exposure through the I per cent phenylalanine solution; and that 53 per cent survived 30 seconds, and none survived I 20 seconds through the saturated tyrosine solution.

It is thus seen that, under the conditions of our test, $B$. coli is by no means perfectly protected from killing when wave lengths

20 The action of ultra-violet light on certain bacteria in relation to specific absorption by amino acids, by F. I. Harris and H. S. Hoyt, in University of California Publications in Pathology, 2, No. 21, pp. 245-250; 1919. 
236 to $297 \mathrm{~m} \mu$ are screened out provided sufficiently long exposures are made. It is, therefore, incorrect to conclude that bactericidal effect is restricted to wave lengths absorbed by such substances as tyrosine and phenylalanine. It must be observed in passing that the intensity and range of absorption by solutions of these substances vary according to the concentration of the solution and the thickness of the layer through which the light passes. In the living bacterial cell the conditions in these respects would be very different from those obtaining in the experiments reported.

\section{EFFECT OF INTENSITY UPON ABIOTIC ACTION}

In various practical problems, such as, for example, the sterilization of water, it is of importance to determine the effect of the intensity of the radiation stimulus upon the time of exposure required to produce a fixed, though not necessarily complete, mortality in a culture of bacteria.

In the present experiments the intensities used were $I \div \mathrm{I}$, $I \div \mathrm{Io}$, and $I \div 5 \mathrm{O}$. In one series of experiments, using the unfiltered radiation, $N_{1}$, the corresponding times of exposure were 2,20 , and 100 seconds, respectively. As shown in the upper horizontal row of illustrations, in Figure ro, a two-second exposure to $I \div \mathrm{I}$ effected complete killing of the $B$. coli, whereas the roosecond exposure to $I \div 50$ was not sufficiently prolonged to kill all the bacteria. In other words, there is no exact relation between the intensity and the time of exposure.

This is illustrated to better advantage by selecting Petri dishes which have suffered the same bactericidal action, as shown in the lower horizontal row of photographs in Figure ro, and noting the time required to produce the same effect.

When using the filtered radiation, obtained by means of the mica screen, $N_{2}$, the bactericidal action is not so rapid and is, therefore, less subject to errors in timing the exposures. In Figure I I the upper horizontal row of photographs shows the central (exposed) parts of the inoculated Petri dishes, having approximately the same number of surviving colonies of $B$. coli; the time of exposure being Io seconds for $I \div \mathrm{I}$ and 600 seconds for $I \div 50$.

In this same illustration the central and the lower horizontal rows of photographs show the number of surviving colonies after an exposure of 15 seconds for $I \div \mathrm{I}$. From these two rows of photographs it may be noted that, in order to produce the same mortality when using an intensity of $I \div 50$, as was obtained with 
Scientific Papers of the Bureau of Standards, Vol. 19

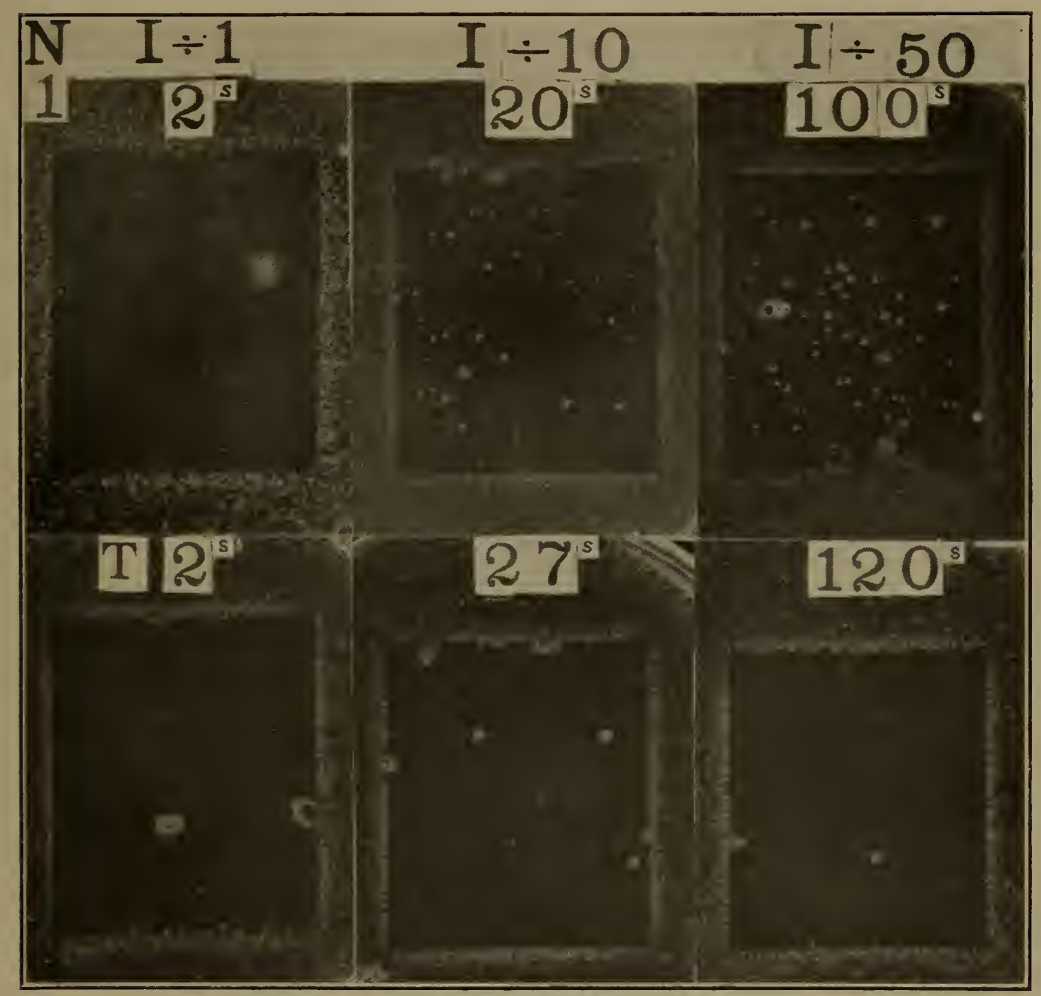

FIG. I0.-Effect of intensity upon the time of exposure required to obtain the same killing aclion, using unfiltered ultra-violet radiation 
Scientific Papers of the Bureau of Standards, Vol. 19

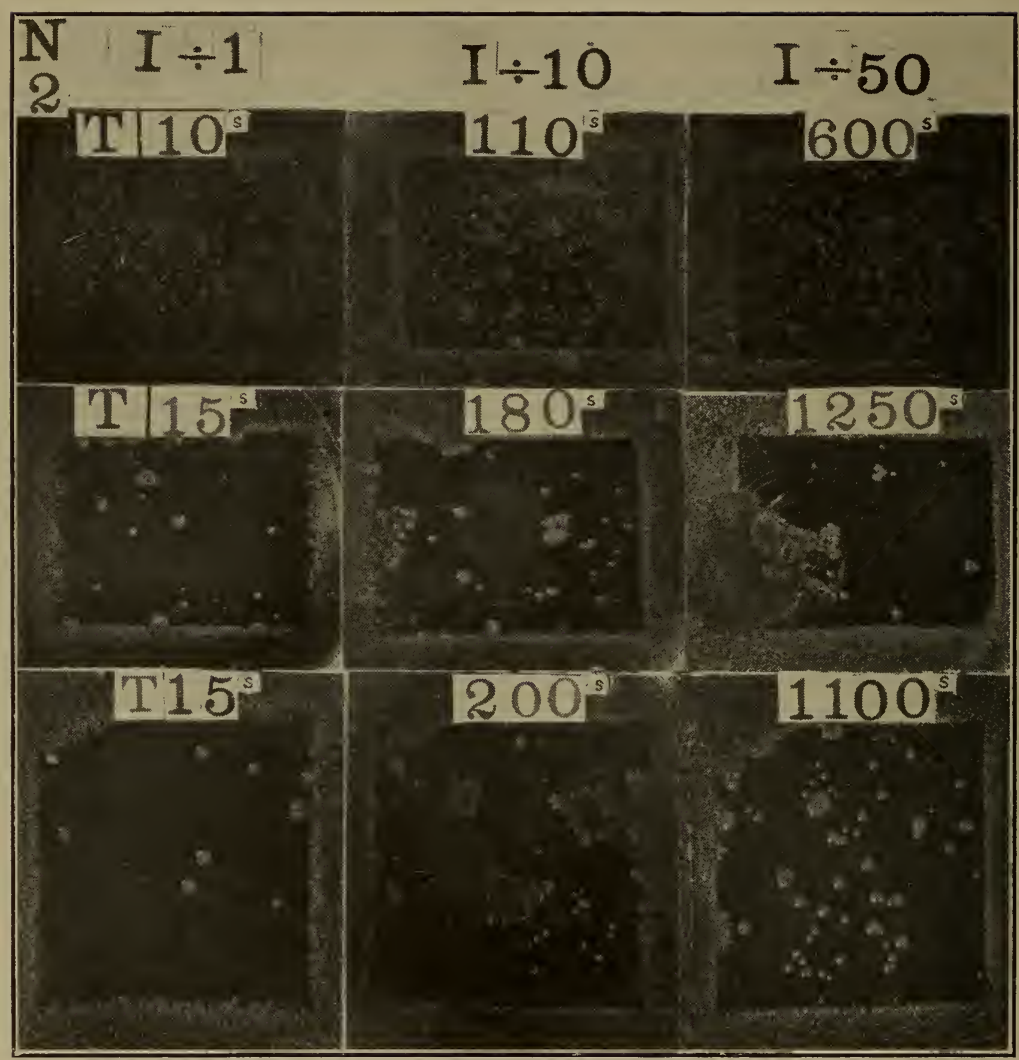

FIG. II.-Effect of intensity upon the time of exposure required to obtain the same killing action upon bacteria, using filtered ultra-violet radiation 
$I \div \mathrm{I}$, the time of exposure lies between $\mathrm{I}, \mathrm{IO0}$ and $\mathrm{I}, 250$ seconds, or an intensity-time factor lying between 73 and 83 . In Figure I I, the plates for 200 and I, 250 seconds were damaged by blotches of moisture, but this does not interfere with the interpretation of the clear areas. The results obtained when the time of exposure was increased by the same ratio that the intensity of radiation was decreased are given in Table 5 . It will be noted that with lowering of the intensity a proportionate increase in the time of exposure falls short of bringing about an equal killing effect. Screens with less transmission than $N_{2}$ were not used because of the exceedingly long exposures that would have been required with the low intensity of radiation.

TABLE 5.-Survivors of B. coli (Percentages) at Different Intensities and Exposure Time Factors

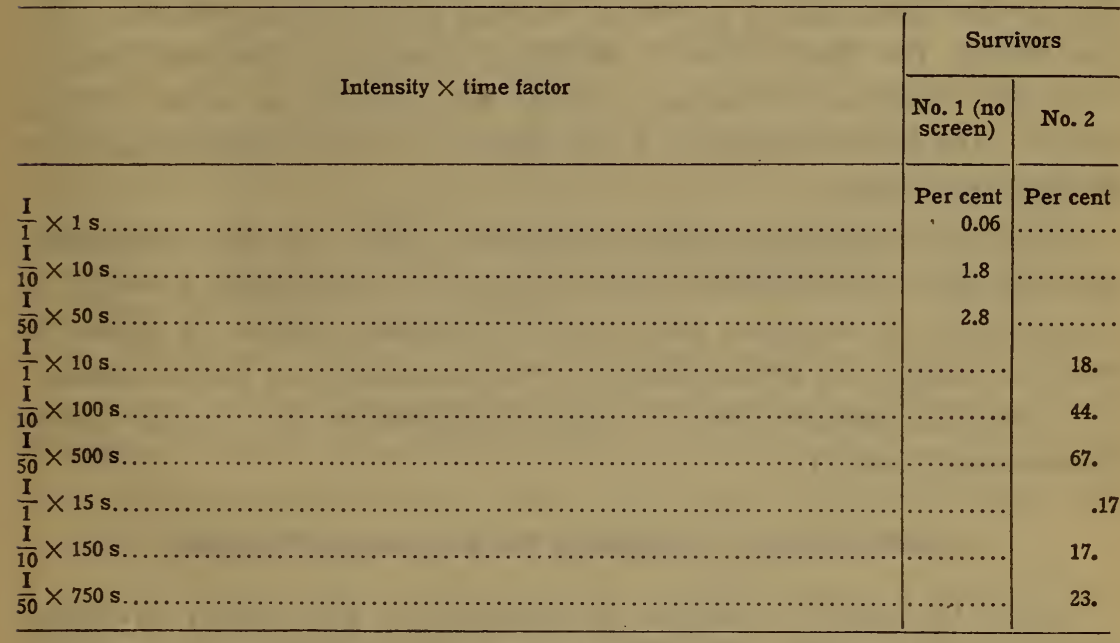

It may be noted that the percentage of survivors rises with exposures of lessened intensity in spite of the time of exposure having been proportionately increased.

In this test, as well as in a subsequent one, exposures were made at various short periods before and after the times selected for obtaining the data given in Table 5. From observation of the results, those times of exposure were selected that gave approximately the same killing effect (see figs. Io and I I), and their ratios were calculated. The results are given in Table 6. 
TABLE 6.-Giving the Ratios of the Time of Exposure Required to Produce the Same - Killing of $B$. coli, Using Different Intensities

\begin{tabular}{|c|c|c|c|}
\hline \multirow{2}{*}{ Screen } & \multicolumn{3}{|c|}{ Intensity } \\
\hline & $\mathrm{I} / 1$ & $\mathrm{I} / 10$ & $\mathrm{I} / 50$ \\
\hline No. $1 .$. & $\begin{array}{l}1 \\
1 \\
1 \\
\end{array}$ & $\begin{array}{l}14 \\
18 \\
10 \\
\end{array}$ & $\begin{array}{l}60 \\
90 \\
55\end{array}$ \\
\hline Average, three tests. & 1 & 14 & 68.3 \\
\hline No. $2 \ldots \ldots \ldots \ldots \ldots$ & $\begin{array}{l}1 \\
1 \\
1 \\
1\end{array}$ & $\begin{array}{l}13 \\
13 \\
12 \\
12\end{array}$ & $\begin{array}{l}90 \\
73 \\
67 \\
75\end{array}$ \\
\hline Average, four tests. & 1 & 12.5 & $\overline{76.2}$ \\
\hline
\end{tabular}

Since killing was very rapid at full intensity with the unscreened light, $N_{1}$, there was a chance for some inaccuracy in the data due to the difficulty of correctly timing the short exposures. On the whole, the data show a definite increase in the time ratios, over the reciprocal intensity ratios $I \div 10$, for an equal killing effect. Using the intensity $I \div 50$ there is a very marked increase in the time ratios.

From the foregoing data it appears that, for the intensities used in this investigation, when using low intensities $(I \div 50)$ it is necessary to increase the time of exposure about 75 times in order to effect the same killing as was obtained on full intensity. The practical application to water sterilization and similar problems seems evident.

\section{THE ENERGY REQUIRED TO KILL A BACTERIUM}

It will be useful to obtain an estimate of the energy involved in germicidal action. For this purpose it is sufficient to consider radiation of wave lengths less than $3 \mathrm{I} 3 \mathrm{~m} \mu$, which has a rapid abiotic action. By utilizing the above-mentioned additive and subtractive principle we shall confine our attention to the spectral region which includes the emission lines at 240 to $305 \mathrm{~m} \mu$.

The experimental tests were made by mounting two or three pieces of mica or glass side by side upon a perforated cardboard support, which was then placed over the Petri dish.

The mica screen, No. 3, already mentioned, which consists of two well-defined areas of different thickness is well adapted for performing the experiment in this manner. The bactericidal action under the two areas progresses simultaneously, using two different intensities of radiation, while all other factors, such as, 
for example, temperature, humidity, etc., within the Petri dish remain constant.

Probably the most conspicuous example of increasing the speed of bactericidal action observed in the present investigation is by the use of the above-mentioned mica screen No. 3. As shown in Table $\mathrm{I}$, the (calculated) difference in transmission of the radiation of wave lengths 313 to $436 \mathrm{~m} \mu$ amounts to only 4.5 per cent $(0.47 \mathrm{~cm})$ or about $2.3 \times 10^{-6}$ watt per square millimeter. Since the bactericidal action of the radiation in this spectral range is known to be very weak we may consider that this part of the radiation stimulus (relative to the total, which amounts to $5^{2} \times \mathrm{IO}^{-6}$ watts per square millimeter) remained constant.

On the other hand, in the spectral region extending from 240 to $305 \mathrm{~m} \mu$, the intensity of the radiation stimulus transmitted by these two thicknesses of mica differs by 28.3 per cent $(0.34 \mathrm{~cm})$ or about $1.7 \times 1 \mathrm{IO}^{-6}$ watt per square millimeter out of a total of $6 \times 10^{-6}$ watt per square millimeter. As shown in the lower part of the photograph (fig. 5) of the Petri dish which was exposed for I 6 seconds, this 28 per cent additional radiation greatly accelerated the lethal action, causing practically complete killing in 16 seconds, whereas under the thicker part of the mica screen perhaps 50 per cent of the culture survived.

In order to obtain an estimate of the energy required to kill a bacterium it is necessary to consider the size of the object exposed. Published data ${ }^{30}$ show that the average length of $B$. coli is 1.0 to $2.0 \mu$, and the width about $0.5 \mu$. The area of a bacterium exposed to radiation is, therefore, about $8 \times 10^{-7}$ square millimeters.

(a) Abiotic Action, No Screan.-Referring to Table I (No. I to No. 5) the energy value of the most active germicidal radiation (from the mercury arc) of wave lengths $\mathrm{I} 70$ to $280 \mathrm{~m} \mu$, for $I_{\mathrm{o}}$, was observed to be $4.8 \mathrm{~cm}$ or $24 \times 10^{-6}$ watt per square millimeter. It was repeatedly observed that an exposure of one second to the unobstructed radiation, $I_{0}$, effected complete killing of a culture of $B$. coli. Assuming that all the radiation of wave lengths I 70 to $280 \mathrm{~m} \mu$, is intercepted, conserved, and utilized in lethal action, then the total energy required to kill a bacterium amounts to $\left(24 \times 10^{-6} \times 8 \times 10^{-7}=\right) 19 \times 10^{-12}$ watt or $4.5 \times 10^{-12} \mathrm{~g}$ cal.

(b) Abiotic Action, Mica ScreEN No. 2.-Using mica screen No. 2 the spectral range of the most active germicidal rays is confined to the wave lengths 220 to $280 \mathrm{~m} \mu$. The energy value

\footnotetext{
${ }^{30}$ Bergey's Manual of Determinative Bacteriology, Society of American Bacteriologists; r923.
} 
is $(2.2 \mathrm{~cm}$ or $)$ II $\times 1 \mathrm{IO}^{-6}$ watt per square millimeter, or $88 \times \mathrm{IO}^{-13}$ watt per bacterium.

An exposure of about 5 seconds was required to effect complete killing of the $B$. coli under this screen. The total energy used, is therefore, $132 \times 10^{-12}$ watt or $31.4 \times 10^{-12} \mathrm{~g}$ cal. This is seven times greater than was required when the radiation stimulus included rays of wave lengths 170 to $220 \mathrm{~m} \mu$. As already shown, when using an intensity of $I \div 10$, the time of exposure required to effect complete killing is somewhat greater ( 13 instead of ro seconds) than the inverse of the intensity. In the present instance the intensities differ by 2.2. On this basis, if it were merely a question of intensity, then an exposure of about seven seconds would have been sufficient to effect complete killing. It is, therefore, to be concluded that the greater lethal action of the unobstructed radiation is to be attributed to the presence of the short wave-length radiation, extending from I 70 to $220 \mathrm{~m} \mu$,

- which, according to these calculations, have from six to seven times the killing power of the radiation at 220 to $280 \mathrm{~m} \mu$. This, of course, is in agreement with the qualitative data of other investigators cited in the first part of this paper.

To recapitulate, the foregoing experiments and calculations show two important facts: (I) That the total energy of wave lengths I7o to $305 \mathrm{~m} \mu$, required for germicidal action is very small and (2) that, in order to produce a rapid killing action with a quartz-mercury arc lamp, the lethal radiant flux must exceed a threshold value, which for the present may be considered to be of the order of 25 microwatts per square millimeter.

\section{SUMMARY}

Although the literature is replete with reports of investigations of the germicidal action of ultra-violet radiation but little information is at hand regarding the energy relations involved.

In the present investigation an attempt is made to present the results on a radiometric basis, which seems to be the logical procedure in order to obtain some estimate of the germicidal action of different parts of the spectrum.

The subtractive and additive method of attacking the problem was used. The subtractive principle consists in eliminating different portions of the ultra-violet spectrum by means of absorption screens. The additive principle, the use of which appears to be novel, is based upon the discovery of a well-defined absorption 
band at about $260 \mathrm{~m} \mu$, in mica. A small variation in thickness of the mica screen produces a large variation in transmission in this spectral region relative to the rest of the spectrum in which the transmission remains practically constant.

The source of ultra-violet radiation was a quartz-mercury arc lamp. The test organism was Bacterium coli communis suspended in sterile distilled water. This suspension was atomized uniformly over the surface of a Petri dish, containing hardened sterile beef-peptone agar, and then exposed to ultra-violet radiation.

In the preliminary tests it was found that exposure of the standard uninoculated beef-peptone agar to ultra-violet radiation, of the intensities and for the time of exposure used in this investigation; had no effect upon the subsequently seeded surface. However, when using a very high radiation intensity, a subsequent seeding of the surface of the preexposed agar gave no growth, or only a small number of colonies of bacteria.

An investigation was made ( $\mathrm{I}$ ) of the spectral range of bactericidal action, (2) of the effect of varying the intensity of the exciting light, and (3) of the method of exposure, whether continuous or intermittent.

From various experimental data it appears that germicidal action is produced by ultra-violet radiation throughout the spectral range extending from the very short wave lengths (Schumann rays) to and including $365 \mathrm{~m} \mu$. The shortest rays have the most violent lethal action, which decreases in intensity with increase in wave length.

The long wave-length limit of abiotic action is not well defined. Previous investigations have been interpreted as indicating that the long wave-length limit of abiotic action is in the region of about $297 \mathrm{~m} \mu$. In the present investigation, when the time of exposure was sufficiently prolonged, killing of bacteria was obtained through screens which transmitted ultra-violet radiation of wave lengths longer than $297 \mathrm{~m} \mu$, including the $365 \mathrm{~m} \mu$ line. But no abiotic action was obtained thrcugh screens which transmitted only wave lengths longer than $365 \mathrm{~m} \mu$ for the exposures used. The present tests, therefore, show that the long wave-length limit of ultra-voilet abiotic action includes the wave length, $365 \mathrm{~m} \mu$, and explains the bactericidal action obtained in sunlight.

The lethal action of radiation of wave lengths longer than 305 $\mathrm{m} \mu$ was found very slow in comparison with radiation of wave 
lengths less than $280 \mathrm{~m} \mu$, even though the latter was much lower intensity. Using the ultra-violet radiation emanating from the quartz-mercury arc the lethal action of the wave lengths less than $280 \mathrm{~m} \mu$ is estimated to be at least Io times more rapid than that of the wave lengths greater than $305 \mathrm{~m} \mu$.

Tests were made to determine the abiotic action of ultra-violet radiation when the total exposure is applied (I) continuously and (2) intermittently with short or long intervals of rest. No difference in the density of the growth of bacteria could be observed whatever the method of exposure. From this it appears that the intermittent exposure does not have a latent effect, either in stimulating growth or in continuing the lethal action, during the intervals of rest, and that the killing effect is cumulative.

On low intensities the killing action is greatly retarded; for example, using an intensity of $I \div 50$ it was necessary to expose the inoculated plate for 75 to 80 seconds instead of 50 seconds in order to secure the same killing effect as when using unit intensity and unit time. On still lower intensities there are some (although not thoroughly verified) indications of stimulation instead of lethal action.

It is shown that the energy value of the most active germicidal radiation from the quartz-mercury arc of wave lengths $I 70$ to $280 \mathrm{~m} \mu$ required to kill a bacterium is very small, being of the order of $19 \times 10^{-12}$ watt or $4.5 \times 10^{-12} \mathrm{~g}$ cal.

A further deduction is that, in order to produce a rapid abiotic action (in one second) the radiant flux of the germicidal radiation from the quartz-mercury arc must exceed a certain threshold value, which is of the order of 25 microwatts per square millimeter. This is obtained at a distance of about $15 \mathrm{~cm}$ ( 6 inches) from a I Io-volt mercury in quartz arc lamp consuming about 320 watts (8o volts, 4 amperes) in the burner.

WASHINGTON, May 3I, I 924 . 